\title{
Membrane transporters and drought resistance - a complex issue
}

\author{
Karolina M. Jarzyniak ${ }^{1,2}$ and Michał Jasiński ${ }^{1,2}$ * \\ ' Laboratory of Plant Molecular Physiology, Department of Natural Products Biochemistry, Institute of Bioorganic Chemistry Polish Academy of Sciences, \\ Poznań, Poland \\ ${ }^{2}$ Laboratory of Molecular Biology, Department of Biochemistry and Biotechnology, University of Life Sciences, Poznań, Poland
}

\section{Edited by:}

Markus Geisler, University of

Fribourg, Switzerland

Reviewed by:

Maria Cristina Bonza, University of

Milano, Italy

Enrico Martinoia, Universitaet Zuerich, Switzerland

\section{*Correspondence:}

Michat Jasiński, Laboratory of Plant Molecular Physiology, Department of Natural Products Biochemistry, Institute of Bioorganic Chemistry

Polish Academy of Sciences,

Noskowskiego 12/14, Poznań 61-704,

Poland

e-mail: jasinski@ibch.poznan.pl
Land plants have evolved complex adaptation strategies to survive changes in water status in the environment. Understanding the molecular nature of such adaptive changes allows the development of rapid innovations to improve crop performance. Plant membrane transport systems play a significant role when adjusting to water scarcity. Here we put proteins participating in transmembrane allocations of various molecules in the context of stomatal, cuticular, and root responses, representing a part of the drought resistance strategy. Their role in the transport of signaling molecules, ions or osmolytes is summarized and the challenge of the forthcoming research, resulting from the recent discoveries, is highlighted.

\section{Keywords: drought avoidance, drought tolerance, transmembrane allocation, transport systems, abscisic acid}

\section{INTRODUCTION}

Drought is one of the most acute abiotic stressors, commonly encountered by plants; that adversely affects crop production worldwide. Today, the development of plants with an increased capacity to survive during water scarcity combined with a high yield potential is the principal objective of agrobiotechnology.

Over the course of evolution, plants have developed sophisticated mechanisms that allow adaptation and survival during periods of water deficit. These mechanisms serve as candidate pathways for the engineering of enhanced drought stress tolerance. In response to water deprivation, plants exhibit the following strategies: (i) escape, (ii) avoidance, and (iii) tolerance. Droughtescaping plants, such as desert ephemerals, annual crops and pasture plants, complete their life cycle before the onset of acute drought. This is achieved through high metabolic activity, rapid growth, and the acceleration of flowering. Avoidance responses occur in both annual and perennial plants. Such strategies rely on the maintenance of water uptake through the modulation of root architecture. Water loss is also limited by reducing stomatal and cuticular conductance and evaporative surfaces. Drought tolerance is associated with the ability of tissues to withstand low water potential; this is achieved via osmotic adjustment and the synthesis of low-molecular weight proteins that protect plants from damage caused by water deficiency (Bacelar et al., 2012).

Recent progress in plant functional genomics has enabled the identification and characterization of genes involved in many essential steps of the drought stress response. Increasing evidence indicates that various plant membrane transport systems play a significant role in adaptation to drought. Depending on energy needs, translocation through biological membranes occurs in a passive or active manner. Passive transport, also known as facilitated diffusion, occurs through channels and carriers. Active transport is performed by primary and secondary transporters that use ATP hydrolysis and ion gradients, respectively, to drive solutes across membranes (Schulz, 2011). The study of transporters related to signaling molecules, e.g., abscisic acid (ABA), as well as ions and osmolytes paves the way for the development of new drought-tolerant varieties. In this review, membrane transport systems will be presented according to their participation in drought avoidance and tolerance strategies. The role of various transport systems in ABA translocation, stomatal, cuticular, and root responses, as well as osmotic adjustment will be summarized.

\section{ABA IN DROUGHT AVOIDANCE AND TOLERANCE STRATEGIES}

Abscisic acid is a ubiquitous plant hormone and signaling molecule; it controls plant growth and development and modulates the response to environmental stressors. As a phytohormone crucial in drought avoidance strategies, ABA elicits two distinct responses: rapid and gradual. The earliest plant reaction, regulated in an ABA-dependent manner, is the modulation of stomatal aperture; this minimizes the loss of water through transpiration. Exposure to ABA prompts guard cells to decrease their volume and close across the airway pore. This is achieved via changes in ion flux within the guard cell (Finkelstein, 2013). ABA gradually increases hydraulic conductivity and promotes cell elongation in the root, enabling the plant to recover after water shortage (Kudoyarova et al., 2011). By inducing the accumulation of osmotically active compounds, which protects cells from damage, ABA participates in the drought tolerance response (Finkelstein, 2013).

Biosynthetic pathways that result in free, active ABA have been previously reviewed (Finkelstein, 2013). ABA is synthesized from 
precursors, mainly carotenoids and xanthophylls found in plastids. The accumulation of synthesis enzymes has been observed in the veins of vegetative tissues, guard cells, maternal tissues, and embryos (Boursiac et al., 2013). Free ABA is also generated by the deconjugation of the ABA glucosyl ester (ABA-GE), a major ABA conjugate that functions as an $\mathrm{ABA}$ reservoir in the vacuole and endoplasmic reticulum (ER; Lee et al., 2006; Xu et al., 2012; Burla et al., 2013). According to the recent findings, the location of ABA biosynthesis depends on the water status in the environment. In the early stages of soil water deficiency, a root-derived $\mathrm{SO}_{4}{ }^{2-}$ signal is transported to the shoots. Consequently, $\mathrm{ABA}$ is synthesized in the veins of vegetative tissues and promotes stomatal closure (Ernst et al., 2010). ABA biosynthesis also occurs directly in the guard cells in response to low humidity; this ABA is assumed to be sufficient for stomata closure (Bauer et al., 2013). Continuing water shortage results in ABA biosynthesis in the roots and the redistribution of root-derived $\mathrm{ABA}$ through the xylem into the aerial parts of the plant (Goodger and Schachtman, 2010).

\section{ABA TRANSPORTERS}

Recently, the molecular basis of ABA transport has been defined. Two models of transmembrane ABA translocation, based on diffusion and the presence of primary and secondary transporters, are now widely accepted. ABA, as a weak acid, exists in an anionic $\left(\mathrm{ABA}^{-}\right)$, and in a protonated $(\mathrm{ABAH})$ form. The latter, when uncharged, is able to diffuse through the plasma membrane (PM). The diffusion of weak acids has its limitations. An increase in $\mathrm{pH}$ (ABA pKa 4.7) due to drought stress can drastically decrease the pool of apoplastic-diffusible ABAH. This limiting step highlights the necessity of ABA transporters, which increase the amount of ABA accessible to intracellular receptors upon stress conditions (Boursiac et al., 2013).

\section{Primary ABA transporters}

In Arabidopsis thaliana, members of ATP-binding cassette (ABC) family have been shown to be involved in ABA transport. The $\mathrm{ABC}$ proteins have been grouped into eight major subfamilies $(\mathrm{A}-\mathrm{H})$; these subfamilies correspond to phylogenetic pathways and structural features. In regard to protein architecture, the largest known subfamily of $\mathrm{ABC}$ proteins is the $\mathrm{G}$ subfamily. The G subfamily (ABCG) has been divided into the following two distinct groups: (i) the half-size transporters, which were formerly known as the white brown complex (WBC), and (ii) the full-size transporters (also known as the pleiotropic drug resistance transporters - PDRs). ABCGs comprise a single or double set of two basic structural elements: a transmembrane domain (TMD) and a nucleotide-binding domain (NBD) (Verrier et al., 2008). The halfsize AtABCG25/WBC26 transporter, which is expressed mainly in vascular tissues, is an ABA efflux carrier (see Figure 1). Overexpression of this transporter reduces water loss from leaves by facilitating the delivery of ABA to guard cells (Kuromori et al., 2010). By contrast, the full-size AtABCG40 transporter, which is primarily found in guard cells, imports ABA into stomatal cells (see Figure 1). This transporter is necessary for the proper plant response to ABA. Loss-of-function $a b c g 40$ mutants have guard cells with reduced sensitivity to ABA and are more susceptible to drought stress (Kang et al., 2010). Kuromori et al. (2011) reported on a half-size ABCG transporter (AtABCG22/WBC23) that likely enhances ABA influx into guard cells (see Figure 1). A mutation in the gene encoding this protein results in an increase in water transpiration and drought susceptibility. However, the ABA transport activity of the corresponding protein remains to be examined.

The role of $\mathrm{ABC}$ transporters in $\mathrm{ABA}$ transport remains to be functionally analyzed. These multifaceted proteins must be fit into a broader context of functional plasticity. It is tempting to question whether a given $\mathrm{ABC}$ transporter or a closely related group of paralogs, which are widely expressed in various organs (e.g., leaves and roots) and/or have defined substrate specificity $(\mathrm{ABA})$, participates in a coordinated manner in response to drought.

\section{Secondary ABA transporters}

Using a modified yeast two-hybrid system, Kanno et al. (2012) identified a nitrate transporter (NRT1.2) belonging to the NRT1/PTR (Nitrate transporter1/Peptide transporter) family currently known as ABA-IMPORTING TRANSPORTER (AIT1; see Figure 1). The activity of the AIT1 promoter was observed in the vascular tissues of the inflorescence stems, leaves, and roots. After the characterization of loss-of-function mutants and transport assays, it was suggested that AIT1 is an ABA importer that is essential for the regulation of stomatal aperture in the inflorescence stems. Recently, Zhang etal. (2014) identified a new ABA transporter in A. thaliana known as DTX50 (see Figure 1). This protein belongs to the DTX/MATE (The Detoxification Efflux Carriers/Multidrug and Toxic Compound Extrusion) family. Following ABA treatment, AtDTX50 transcripts accumulated in both guard cells and the vascular bundles of leaves. Proteins encoded by AtDTX50 localized to the PM. Transport experiments using Escherichia coli and Xenopus oocytes expressing AtDTX50 revealed that it is an ABA exporter. AtDTX50 transport activity was the highest at an apoplastic $\mathrm{pH}$ of 7.0, which reflects drought conditions. Disruption of AtDTX50 activity resulted in slower wilting; this is a direct consequence of the inability to remove excess $\mathrm{ABA}$ and the hyperaccumulation of the hormone in leaves. In A. thaliana with dysfunctional DTX50, stomata closed more rapidly; this resulted in an increased tolerance to drought. Insertion mutants displayed growth retardation and ABA hypersensitivity. Overall, these results provided strong evidence that AtDTX50 plays an essential role in the control of ABA accumulation in various cell types; this protein is the second ABA efflux transporter identified, after AtABCG25 (Zhang et al., 2014).

\section{ABA CONJUGATE TRANSPORTERS}

It has been proposed that ABA-GE conjugates are actively transported into the vacuoles of mesophyll cells by ABC transporters (see Figure 1) or proton gradient-driven transporters (Burla et al., 2013). Two members of the A. thaliana ABCC/MRP (multidrug resistance-associated protein) subfamily, AtABCC1/MRP1 and AtABCC2/MRP2, are localized in tonoplast and exhibit ABA-GE transport activity in a yeast heterologous expression system. According to microarray analysis, the expression of ABCC2 is induced upon drought. In addition to ABCCs, secondary 


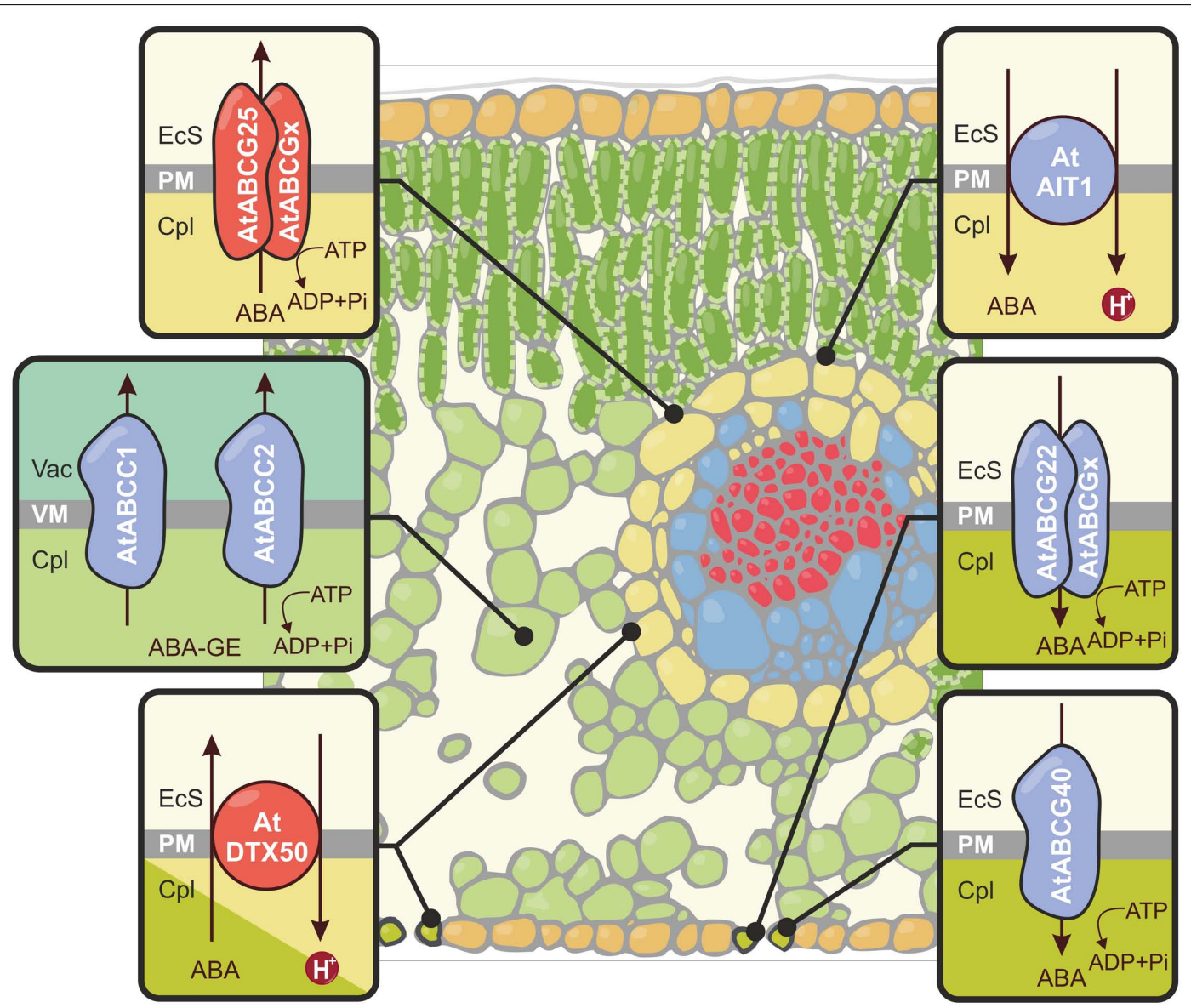

FIGURE 1 | Schematic representation of abscisic acid (ABA) and ABA glucosyl ester (ABA-GE) translocation across the plasma membrane (PM) and the tonoplast (VM) in leaf tissue. The transporters that function as exporters (AtABCG25, AtDTX50) are shown in red, and importers
(AtABCG40, AtABCG22, AtAlT1/NRT1.2, AtABCC1, AtABCC2) are presented in blue. To fulfill their role, the half-size $A B C$ transporters form homo- or heterodimers. The composition of AtABCG25 and AtABCG22 dimers has not been yet determined. EcS, extracellular space; Cpl, cytoplasm; Vac, vacuole. transporters also participate in the vacuolar sequestration of ABA conjugates; these transporters are presumably members of the MATE family (Burla et al., 2013).

\section{ION MOVEMENT AND STOMATAL CLOSURE UPON DROUGHT}

The reliable and fast adjustment of stomatal aperture is necessary for effective drought avoidance in plants. A rapid response reduces the amount of water lost, increases water use efficiency, and allows plants to survive (Farooq et al., 2009). There are two pathways leading to stomatal closure, passive, and active. In the passive pathway, turgor loss occurs without a reduction of the solute content of the guard cells (McAdam and Brodribb, 2014). Because the passive pathway cannot sufficiently protect the plant against drought, active solute loss is necessary. The movement of osmoregulatory ions $\left(\mathrm{K}^{+}, \mathrm{Cl}^{-}\right.$, and malate $\left.{ }^{2-}\right)$ across guard cell membranes and the gluconeogenic conversion of malate into starch, accompanied by water export through aquaporins (AQPs), results in a decrease in cell volume. Turgor is lost, and the stomata finally close. Mature guard cells have no plasmodesmata; the existence of channels, transporters, and pumps in the PM are required (Lawson and Blatt, 2014).

\section{$\mathrm{Ca}^{2+}$ PERMEABLE CHANNELS}

In the active solute loss scenario, $\mathrm{ABA}$ is imported into guard cells by $\mathrm{ABCG} 40$ in response to drought. This triggers the production of reactive oxygen species (ROS) such as hydrogen peroxide $\left(\mathrm{H}_{2} \mathrm{O}_{2}\right)$ and nitric oxide (NO) and cytoplasmic $\mathrm{Ca}^{2+}\left(\left[\mathrm{Ca}^{2+}\right]_{\text {cyt }}\right)$ increases (Kim et al., 2010). The level of oxidative stress is controlled by a group of low molecular antioxidant compounds known as flavonols (Watkins et al., 2014). The molecular nature of flavonol transporters in these particular cells remains to be elucidated. However, the action of such proteins indirectly influences the aperture of guard cells. Members of the MATE and ABC protein families are involved in the transport of secondary plant metabolites, including flavonoids (Zhao and Dixon, 2010). The accumulation of $\left[\mathrm{Ca}^{2+}\right]_{\text {cyt }}$, is possible due to $\mathrm{Ca}^{2+}$-permeable channels located in the tonoplast and the PM (see Figure 2). These proteins are encoded by genes belonging to the TPC1 (twopore channel 1), CNGC (cyclic nucleotide-gated channel), and GLR (glutamate receptor-like) families. TPC1 has been classified as slow vacuolar (SV) non-selective cation channel that is regulated by luminal $\mathrm{Ca}^{2+}$ (Islam et al., 2010). In A. thaliana, members of the CNGC and GLR families, namely AtCNGC5, AtCNGC6, 


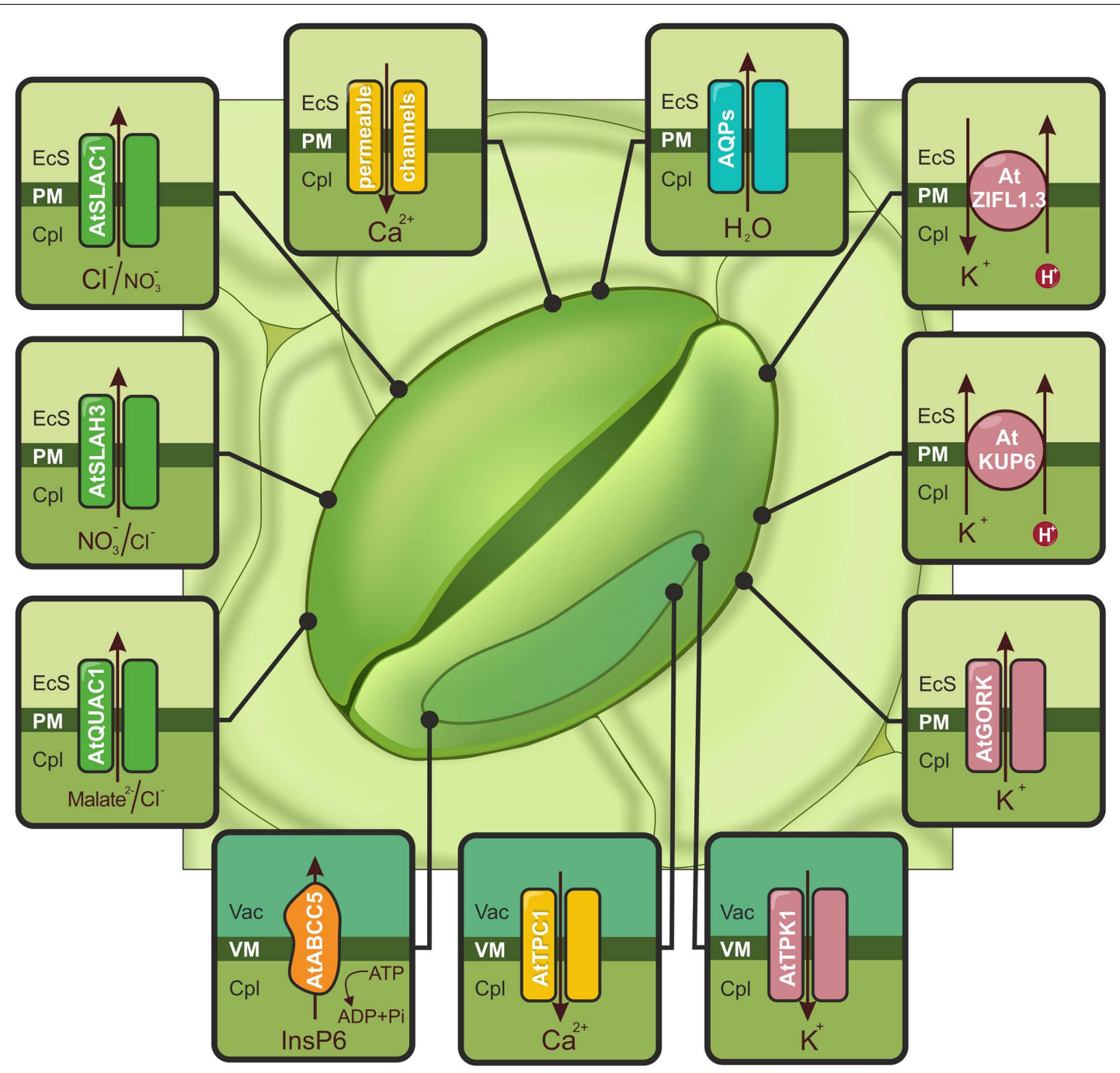

FIGURE 2 | Schematic illustration of ion channels, aquaporins (AOPs) and transporters activated by drought or ABA and controlling stomatal closure. The accumulation of cytoplasmic $\mathrm{Ca}^{2+}\left(\left[\mathrm{Ca}^{2+}\right]_{\text {cyt }}\right)$, is possible due to $\mathrm{Ca}^{2+}$-permeable channels (yellow) localized in the PM (e.g., AtCNGC5, AtCNGC6, AtGLR3.1) and the tonoplast (AtTPC1). Increasing the amount of calcium activates S-type (AtSLAC1 and AtSLAH3) and R-type (AtQUAC1) channels, which are indicated in green. AtABCC5/MRP5 (orange), localized to the vacuolar membrane (VM), is a regulator of $\mathrm{Ca}^{2+}$-permeable and S-type channels. The actions of the Sand R-type channels induce membrane depolarization and activate $\mathrm{K}^{+}$ flow through AtGORK and AtKUP6 (pink) from guard cells. The release of $\mathrm{K}^{+}$from the vacuole is mediated by the AtTPK1 channel (pink). Additionally, stomatal closure is regulated by the action of the AtZIFL1.3 isoform, indicated in pink. AQPs are responsible for the outflow of water (e.g., VfPIP1), shown in blue. EcS, extracellular space; Cpl, cytoplasm; Vac, vacuole. and AtGLR3.1, are PM-located $\mathrm{Ca}^{2+}$ channels (Cho et al., 2009; Wang etal., 2013). The distinguishing feature of CNGC proteins is cGMP-dependent activation (Wang et al., 2013), which is also required for an increase in $\left[\mathrm{Ca}^{2+}\right]_{\text {cyt }}$ (Dubovskaya et al., 2011). The long-term $\mathrm{Ca}^{2+}$-programmed stomatal response that prevents guard cell reopening is established by AtGLR3.1 (Cho et al., 2009).

\section{ANION CHANNELS (S-TYPE AND R-TYPE)}

The ABA-induced signal cascade results in the activation of S-type (slow-activating sustained) and R-type (rapid-transient) anion channels, which cause PM depolarization. Simultaneously, the inhibition of $\mathrm{H}^{+}$-ATPase and inward $\mathrm{K}^{+}$channels (KAT1/KAT2) prevents the hyperpolarization of the PM (Osakabe et al., 2014). Recent studies have identified the genes encoding $\mathrm{S}$ and R-type anion channels. The A. thaliana SLAC1 (slow anion channelassociated 1) protein is a PM-localized (Negi et al., 2008; Vahisalu et al., 2008) S-type anion channel with a preference for $\mathrm{Cl}^{-}$and $\mathrm{NO}_{3}{ }^{-}$(see Figure 2; Geiger et al., 2009; Lee et al., 2009b). This protein operates mainly in response to $\mathrm{ABA}, \mathrm{CO}_{2}, \mathrm{Ca}^{2+}, \mathrm{NO}$, and $\mathrm{H}_{2} \mathrm{O}_{2}$ (Vahisalu et al., 2008). Mutations in SLAC1 result in the excessive accumulation of anions, such as $\mathrm{Cl}^{-}$, in cell protoplasts and the disruption of stomatal closure (Negi et al., 2008; Vahisalu etal., 2008). Phosphorylation at distinct sites enables SLAC1 activation by both calcium-dependent and calcium-independent pathways downstream of ABA (Maierhofer et al., 2014). A second 
S-type anion channel, SLAH3 (SLAC homolog 3), is expressed in A. thaliana guard cells (Geiger et al., 2011). In contrast to its homolog, SLAH3 has higher permeability toward $\mathrm{NO}_{3}{ }^{-}$than $\mathrm{Cl}_{2}{ }^{-}$(see Figure 2; Geiger et al., 2009, 2011; Lee et al., 2009b). AtMRP5/ABCC5, a vacuolar inositol hexakisphosphate (InsP6) transporter from the $\mathrm{ABC}$ transporter family, may be a central regulator of $\mathrm{Ca}^{2+}$-permeable and S-type anion channels in the $\mathrm{PM}$ of guard cells. This regulation is possible due to the complexing of divalent cations by InsP6 or the triggering a continuous efflux of $\mathrm{Ca}^{2+}$ into the cytosol by an InsP6-regulated channel (see Figure 2; Nagy et al., 2009). A member of the aluminum-activated malate transporter family in A. thaliana, QUAC1/ALMT12 (quick anion channel 1/aluminum-activated anion channel 12), has been identified and classified as malate-sensitive R-type anion channel (see Figure 2; Meyer et al., 2010) or a chloride and nitrate current facilitator (Sasaki et al., 2010). Loss of QUAC1 function results in impairment of stimulus-induced stomatal closure (owing to factors such as $\mathrm{ABA}, \mathrm{CO}_{2}, \mathrm{Ca}^{2+}$; Meyer et al., 2010; Sasaki et al., 2010). Compared to our understanding of anion influx across the tonoplast, the molecular mechanisms of efflux from the vacuole are poorly understood.

\section{POTASSIUM CHANNELS/TRANSPORTERS}

Plasma membrane depolarization activates the efflux of potassium. This transport is facilitated by GORK (guard cell outward rectifying $\mathrm{K}^{+}$) channels, which belong to the Shaker family of voltage-gated ion channels (see Figure 2). GORK transcripts have been widely observed in A. thaliana, especially in guard cells (Becker etal., 2003; Hosy et al., 2003), where they represent the only outward-rectifying $\mathrm{K}^{+}$channel (Eisenach et al., 2014). The inhibition of GORK activity in guard cells results in defects in $\mathrm{K}^{+}$efflux and a lower rate of stomatal closure (Hosy et al., 2003). Osakabe et al. (2013) identified stress-responsive $\mathrm{K}^{+}$uptake permeases (KUPs), which share redundant functions with GORK channels (see Figure 2). The KUP6 and KUP8 proteins in A. thaliana function as $\mathrm{K}^{+} / \mathrm{H}^{+}$symporters. KUP6, which is highly up-regulated in response to the ABA treatment and water deficit, is localized to the PMs of guard cells, root tip cells and vascular tissues. KUP6-overexpressing lines were more tolerant to drought. A kup68g double mutant line (with combined kup6 and kup8 mutations in addition to mutation in the gork potassium channel) had impaired stomatal closure and ABA sensitivity; this mutant also had greater stomatal conductance and water loss rates (Osakabe et al., 2013). An isoform of the ZIFL1 (zinc-induced facilitator-like1) transporter, which belongs to the major facilitator superfamily (MFS), proved to be a modulator of stomatal aperture and conferred drought stress tolerance. The PM-localized AtZIFL1.3 protein possesses $\mathrm{H}^{+}$-coupled $\mathrm{K}^{+}$transport activity, and its overexpression resulted in more efficient stomatal closure (see Figure 2; Remy et al., 2013). The main cellular depository of ions, including potassium, is the vacuole. The release of $\mathrm{K}^{+}$from the vacuole is mediated by channels and transporters localized to the tonoplast. TPK1, a member of the two pore $\mathrm{K}^{+}$channel (TPK) family, is responsible for vacuolar $\mathrm{K}^{+}$translocation in guard cells (see Figure 2). The removal of TPK1 was associated with a weak phenotype; most often the stomatal closure was slower, but the opening kinetics were normal (Gobert et al., 2007).

\section{WATER CHANNELS}

The outflow of water results in a reduction in guard cell turgor and stomatal closure; this is mediated by AQPs, which are membrane channels that belong to the MIP (major intrinsic protein) family (see Figure 2; Heinen et al., 2009). AQPs may form homo- and heterotetramers, with each monomer defining a single pore. Based on amino acid similarity and membrane localization, AQPs are divided into five subgroups; for a review, see (Maurel et al., 2008; Chaumont and Tyerman, 2014). The expression of several genes encoding AQPs belonging to the PIP (PM intrinsic proteins) and TIP (tonoplast intrinsic proteins) subgroups was up-regulated in leaves, mainly in the guard cells, in drought stress conditions (Heinen et al., 2009). Heinen et al. (2014) have identified Zea mays PIPs that are localized to stomatal complexes (mainly ZmPIP1;1, ZmPIP1;3, ZmPIP2;2) and presumably participate in stomatal movement (Heinen et al., 2014). The expression of PIP1 from Vicia faba and Brassica juncea improved drought resistance in A. thaliana and Nicotiana tabacum plants, respectively, through the promotion of stomatal closure (Cui et al., 2008; Zhang et al., 2008).

\section{CHANNELS/TRANSPORTERS INFLUENCING STOMATAL OPENING}

Proteins that regulate stomatal movements by supporting swelling belong to a separate group of transporters. The disruption of $\mathrm{Cl}^{-}$(AtClCc, AtALMT9), $\mathrm{K}^{+}$(AtNHX1, AtNHX2, AtCHX20), and $\mathrm{NO}_{3}{ }^{-}$(AtNRT1.1, AtCLCa) channels/transporters, as well as the AtMRP4/AtABCC4 protein, results in a delay in stomatal opening (Guo et al., 2003; Klein et al., 2004; Padmanaban et al., 2007; Jossier etal., 2010; De Angeli et al., 2013; Andres et al., 2014; Wege et al., 2014). Phosphorylation-dependent changes in the activity of AtCLCa enable the protein to perform dual roles, in anion sequestration in the vacuole during stomatal opening and in anion release during stomatal closure, in response to ABA (Wege et al., 2014). Mutations in a malate importer protein (AtABCB14) result in accelerated stomatal closure (Lee et al., 2008). Mutations in AtALMT9, AtNRT1.1, and AtMRP4 transporters result in the impairment of stomatal responses and are associated with increased drought tolerance (Guo et al., 2003; Klein et al., 2004; De Angeli et al., 2013).

\section{CUTICLE DEPOSITION AS A FACET OF DROUGHT AVOIDANCE}

The formation of the plant cuticle, which covers the surface of all aerial organs, is a crucial plant adaptation to terrestrial habitats. This specialized cell wall (CW) component, which is synthesized exclusively by aerial epidermal cells, consists of wax embedded in (intracuticular) and layered on (epicuticular) a lipid polyester matrix called cutin. The major function of the cuticle is to protect the plant from unfavorable environmental conditions, including drought, by limiting non-stomatal water transpiration (Yeats and Rose, 2013). In A. thaliana, the biosynthesis of cuticle components is induced by water deficiency (Kosma et al., 2009). Recent studies demonstrated that the increased accumulation of cuticular waxes is associated with drought resistance (Yang et al., 2011; Zhu et al., 2014) and ABA treatment (Seo et al., 2011).

During cuticle deposition, the trafficking of wax and cutin precursors occurs from the ER across the PM and CW to the plant surface (Yeats and Rose, 2013). 


\section{INTRACELLULAR TRANSLOCATION OF CUTICULAR COMPONENTS}

To date, the intracellular mechanism of wax and cutin precursor trafficking remains unclear. Several hypothetical pathways to the PM have been suggested (see Figure 3). These precursors might reach the $\mathrm{PM}$ via the following routes: (i) direct relocation at ER-PM contact sites (Samuels and McFarlane, 2012); (ii) transport by cytosolic carrier proteins (e.g., Acyl-CoA binding proteins - ACBPs; Li-Beisson et al., 2010); (iii) vesicular translocation in oleosome bodies coated by oleosin-like proteins; (iv) translocation in uncoated vesicles that sequestrate the cuticular lipids into lipid rafts (Schulz and Frommer, 2004); or (v) Golgi mediated exocytosis (Samuels et al., 2008). Through mutant analysis combined with live cell imaging, electron microscopy and chemical phenotyping, McFarlane et al. (2014) demonstrated that the movement of intracellular wax requires vesicle traffic mediated by Golgi- and trans-Golgi networks. However, AtACBP1 has been shown to contribute to the formation of the stem cuticle; dysfunction in this protein resulted in a reduction in wax and cutin monomer composition. Moreover, AtACBP1 exhibits biding activity to wax precursors (Xue et al., 2014). The cytosol-localized protein LjLTP3, a member of the LTP (lipid transfer protein) family, is able to bind lipids and confers drought tolerance in Lotus japonicus.

\section{TRANSPORT OF CUTIN AND WAX PRECURSORS ACROSS THE PLASMA MEMBRANE}

Members of the ABC transporter family mediate the flux of cuticular components through the PM. Two half-size ABC transporters, named AtABCG12/WBC12/CER5 (Pighin et al., 2004) and AtABCG11/WBC11/DSO/COF1 (Bird et al., 2007; Luo et al., 2007; Panikashvili et al., 2007; Ukitsu et al., 2007), are involved in the secretion of cuticle precursors into the apoplastic environment (see Figure 3). Mutation of both genes results in a significant reduction in the stem wax load (approx. 50\%); a major depletion in C29 alkane, the major component of cuticular waxes in stems, is also observed (Pighin et al., 2004; Bird et al., 2007). The

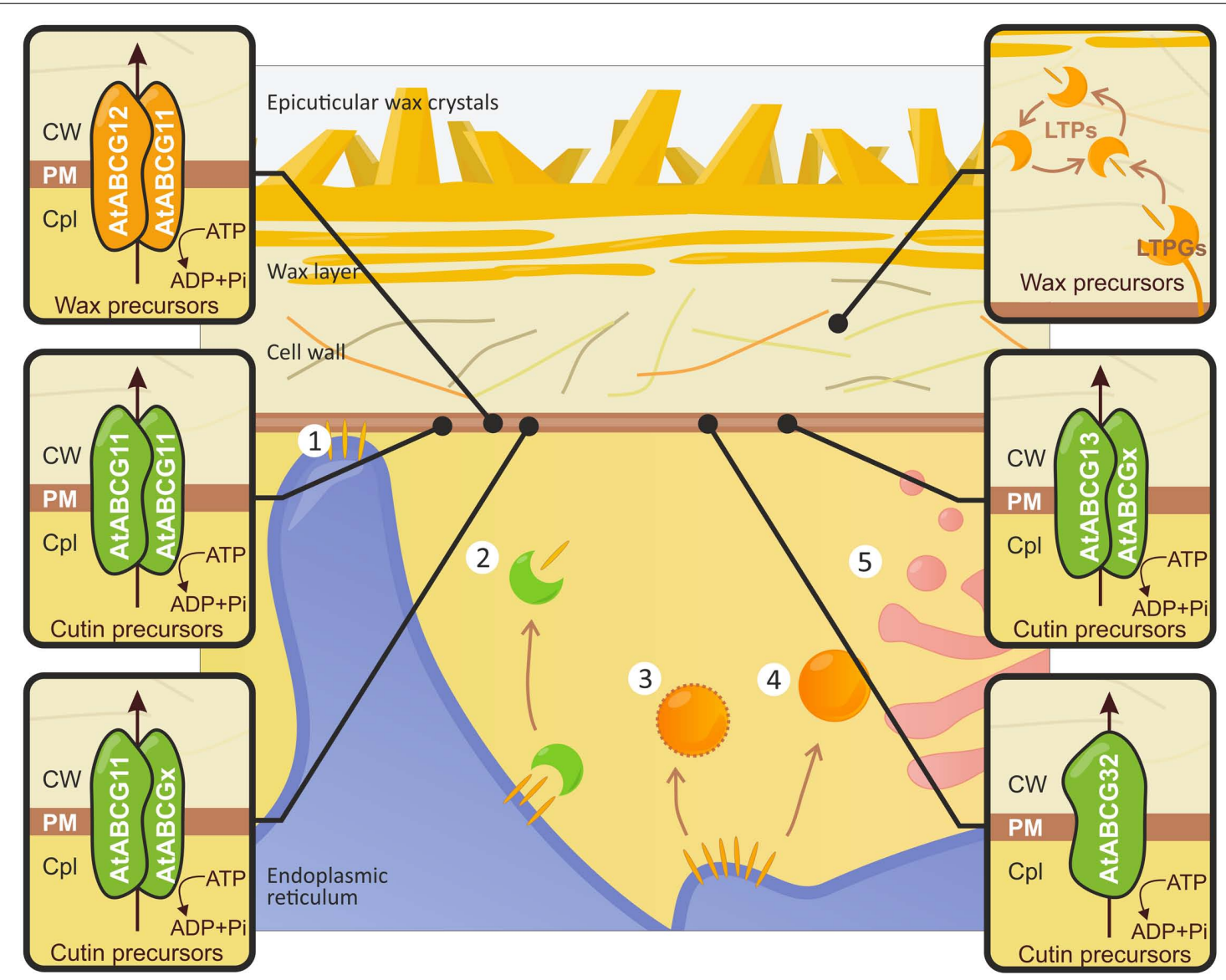

FIGURE 3 | Schematic illustration of cuticular lipid translocation. Different scenarios describing the transport of wax precursors (orange disks) from the endoplasmic reticulum (ER) to the PM have been proposed. Cuticular lipids may be (1) relocated at ER-PM contact sites, (2) grasped by ACBPs (e.g., AtACBP1; green crescent-shaped bodies), transported by (3) coated oleophilic bodies, (4) uncoated vesicles, or (5) the Golgi-mediated secretory pathway. The translocation of wax and cutin precursors through the $\mathrm{PM}$ is a complex action involving several $A B C$ transporters, which are indicated in orange and green, respectively. The latter are either half-size proteins (AtABCG11, AtABCG12, AtABCG13), which function as homo- or heterodimers, or full-size transporters (AtABCG32). Often composition of the homo- or heterodimers defines the profile of the transported substrate (see the text for details). The transport of wax precursors across the cell wall to the plant surface is mediated by LTPGs (e.g., AtLTPG1 and AtLTPG2) in association with yet unknown LTPs. CW, cell wall; Cpl, cytoplasm. 
total amount of wax in the epidermis remains unchanged, indicating that the absence of these two proteins impedes wax transport rather than biosynthesis. AtABCG11 is also likely involved in the translocation of cutin monomers in vegetative and reproductive organs and the transport of suberin in roots (Panikashvili et al., 2007, 2010). The evidence that AtABCG11 forms homo- and heterodimers with AtABCG12 comes from bimolecular fluorescence complementation and protein trafficking assays (McFarlane et al., 2010). AtABCG11 also plays a dominant role in the created complex; ABCG12 could not traffic to the PM in the absence of ABCG11, whereas ABCG11 trafficking was independent of ABCG12 (McFarlane et al., 2010). The half-size ABCG transporter from Solanum tuberosum (StABCG1) was shown to contribute to the export of suberin components across the PM (Landgraf et al., 2014). Silencing of the StABCG1 gene, which is expressed mainly in the roots and tuber periderm, results in a reduction in esterified suberin monomers; this is accompanied by an accumulation of the presumed suberin precursors. Root and tuber morphology was altered, and tubers were more susceptible to drought (Landgraf et al., 2014). The putative ortholog of AtABCG12 found in the moss species Physcomitrella patens is involved in the transport of a wax precursor. This finding suggests that the role of ABCG transporters, particularly halfsize transporters, in the movement of cuticle components is evolutionarily conserved among land plants (Buda et al., 2013). Loss-of-function in AtABCG13/WBC13 (another half-size ABCG transporter that belongs to the ABCG12 clade) results in a significant depletion in petal cutin monomers; this result indicates that the protein plays a role in cutin deposition in flowers (see Figure 3; Panikashvili etal., 2011). The full-size ABCG transporter (AtABCG32) has been shown to contribute to the formation of functional cuticles (see Figure 3; Bessire et al., 2011). Knockout mutations in AtABCG32 result in a significant increase in cuticle permeability in leaves and flowers, as well as in water loss from rosettes and herbicide sensitivity. The ultrastructural changes in the cuticle were associated with reduced amounts of minor aliphatic cutin monomers; these monomers are most likely exported from epidermal cells by AtABCG32. The AtABCG32 monocot orthologs OsABCG31 1 and HvABCG31 may also be involved in cuticle deposition. Loss-of-function mutations in these genes, both in Oryza sativa and in Hordeum vulgare, result in water retention deficiency phenotypes (Chen et al., 2011).

Members of the ABCG subfamily in A. thaliana are also required for proper pollen coat (extracellular matrix) and exine (outer wall) formation. These structures protect gametophytes in unfavorable environmental conditions. Dysfunction in AtABCG9/WBC9 and AtABCG31 proteins results in reduced steryl glycoside levels and altered pollen coat morphology. Correct morphology is essential for pollen coat maturation. A double mutant exhibited increased water loss upon exposure to dry air (Choi et al., 2014). The AtABCG26/WBC27 protein participates in exine deposition in the pollen, presumably by transporting sporopollenin precursors (Quilichini et al., 2010; Choi et al., 2011; Dou et al., 2011). An ortholog in O. sativa (OsABCG15) is crucial for anther cuticle and pollen exine formation (Wu etal., 2014).

\section{TRANSPORT OF CUTICULAR COMPONENTS THROUGH THE CELL WALL TO THE CUTICLE}

Once cuticular components have been moved across the cell membrane, they must pass the hydrophilic CW to reach the cuticle. Movement through the extracellular matrix appears to be facilitated by LTPs. Two members of the LTP family (LTPG1 and LTPG2) are defined as GPI-anchored (glycosylphosphatidylinositol-anchored) proteins. These proteins are located at the exterior face of the PM and are possibly involved in wax export (see Figure 3; Debono et al., 2009; Lee et al., 2009a; Kim et al., 2012). Disruption of AtLTPG1 or its homolog AtLTPG2 modifies the structure of the cuticular layer and reduces the amount of C29 alkane; this is also seen in AtABCG12 and AtABCG11 mutants (Debono et al., 2009; Lee et al., 2009a; Kim et al., 2012). The expression of LTPG1 can complement wax scarcities in ltpg1 mutant lines (Debono et al., 2009). Compared to each single mutant, the double mutant exhibited a more severe phenotype (Kim et al., 2012). Taken together, it seems likely that LTPG1 and LTPG2 are functionally overlapping wax exporters. These proteins act either directly by associating with $\mathrm{ABC}$ transporters or indirectly by creating suitable environment for wax efflux (Debono et al., 2009; Kim et al., 2012). The former model assumes that LTPGs are loaded with C29 alkane cargo and transfer it to other extracellular LTPs, which then carry the lipid load to the plant surface (Debono et al., 2009).

\section{ROOT RESPONSES UPON DROUGHT}

In addition to mechanisms that reduce water loss in the aerial parts of plant, drought avoidance also requires strategies based on the regulation of root water uptake; this is achieved by modulating root growth and hydraulic conductivity (Aroca and Ruiz-Lozano, 2012).

\section{TRANSPORTERS PARTICIPATING IN ROOT GROWTH AND DEVELOPMENT}

To increase the volume of potentially accessible water, the integrated action of ABA and auxins promotes root growth and development (Xu et al., 2013b). Several transporters, which belong to distinct gene families, act as key modulators of auxin translocation and subsequent root morphology changes (Petrasek and Friml, 2009; Zazimalova et al., 2010). There are only few examples of extensive crosstalk between the mechanisms that regulate auxin transport, root development, and drought resistance. The expression of an $A$. thaliana vacuolar $\mathrm{H}^{+}$-pyrophosphatase (AVP1) confers tolerance against drought in many plant species, including Lycopersicon esculentum (Park et al., 2005), Saccharum officinarum (Kumar et al., 2014b), N. tabacum (Arif et al., 2013), and Gossypium hirsutum (Pasapula et al., 2011). AVP1 overexpressing plants exhibited greater $\mathrm{PP}_{\mathrm{i}}$-driven sequestration of ions and sugars into the vacuole, increased water retention and increased cell turgor. Auxin transport is also stimulated, enhancing root system development (Park et al., 2005). This adaptation to stress conditions is also possible due to the different subcellular and tissue distribution of isoforms of transporters with similar substrate profiles. The MFS carrier ZIFL1 protein (Remy et al., 2013) is one example. The two splice isoforms of ZIFL1, ZIFL1.1, and 1.3 , both have $\mathrm{K}^{+}$transport activity that likely influences membrane proton gradients, resulting in distinct biological roles in 
roots and guard cells, respectively. The change of $\mathrm{pH}$ that occurs as a consequence of $\mathrm{K}^{+}$translocation results either in stomata closure or the modulation of auxin transport. In this way, plants can control stomata aperture and change root morphology if necessary.

The effects of ABA on root morphogenesis differ between various plant species, especially the effects on the formation of the lateral roots. In A. thaliana, ABA inhibits lateral root formation. In legumes such as Medicago truncatula, ABA promotes the growth of lateral roots and affects the nodulation process. ABA also acts as a negative regulator of the early stages of nodulation (affecting epidermal Nod factor signaling and cytokinin-activated cortex cell division) and suppresses symbiotic nitrogen fixation (Liang et al., 2007; Ding and Oldroyd, 2009). Nodule formation is an energetic cost that must be strictly controlled; nodulation is highly influenced by environmental conditions. It has been proposed that alternations in hormone levels, especially stress hormones such as ABA, serve as shoot derived signals directed at the roots (Ding and Oldroyd, 2009). This fluctuation in ABA levels is the bridge joining nodulation control and the environmental status of the plant. Despite their importance, the mechanisms behind the translocation/control of such signals are still largely unknown.

\section{CHANGING ROOT HYDRAULIC CONDUCTIVITY - AQUAPORINS TAKE ACTION}

Root hydraulic conductivity (L), the water flux across the root surface area, is governed by drought and ABA. In water deficit conditions, root hydraulic conductivity decreases to prevent water outflow from the roots due to progressively decreasing soil water potential (Aroca et al., 2012). Morphological changes in the root tissue and the existence of water channels constitute the main long-term and short-term determinants of root hydraulic conductivity, respectively. The formation of apoplastic barriers, such as Casparian bands and suberin lamellae, prevents cellular death by limiting water outflow into the soil (Lobet et al., 2014). The halfsize ABCGs, StABCG1, and AtABCG11, affect the root suberin content. Therefore, these proteins might be responsible for the proper formation of suberin lamellae (Panikashvili et al., 2010; Landgraf et al., 2014). Rapid and reversible alterations in water permeability are done by controlling the expression and activity of AQPs. AQPs allow for the passive movement of water through a cell-to-cell pathway, which is the major water path during drought (Aroca and Ruiz-Lozano, 2012). The expression of the two aforementioned MIP subgroups, PIPs and TIPs, is greater in roots than in leaves. Moreover, the localization of PIPs has been associated with the presence of root hydrophobic barriers; this finding suggests that these proteins are involved in the regulation of water movement during drought (Chaumont and Tyerman, 2014). Upon water deficit, the expression of several PIPs is down-regulated to reduce water loss (Moshelion et al., 2014). According to Jang etal. (2004), nine out of the thirteen PIP genes expressed in the root (three from the PIP1 group and six from PIP2 group) showed significant reductions in mRNA accumulation in A. thaliana plants exposed to drought. Similarly, in N. tabacum, the expression of PIPs is significantly down-regulated in a manner corresponding to the level of drought stress (Mahdieh et al., 2008); this phenomenon has also been observed in Fragaria vesca (Surbanovski et al., 2013) and Camellia sinensis roots (Yue et al., 2014). Additionally, the ectopic overexpression of $A$. thaliana PIP1;4 and PIP2;5 in $N$. tabacum resulted in increased water loss under dehydration stress (Jang et al., 2007). By contrast, the heterologous expression of the Triticum aestivum aquaporin gene (TaAQP7), which belongs to PIP2 subgroup, conferred drought tolerance in transgenic $N$. tabacum; plants were able to maintain their water status, reduce the accumulation of ROS and prevent membrane damage via an ABA-dependent pathway (Zhou et al., 2012). Concerning TIP AQPs, plants may respond to drought through cell elongation, osmotic adjustment, and the mediation of water transport across the tonoplast (Wudick et al., 2009). The constitutive expression of TIP1 from Panax ginseng, TIP1;2 from the highly drought-resistant Thellungiella salsuginea and TIP2 from Solanum lycopersicum confer tolerance to water deprivation in A. thaliana; an increase in water absorption requires roots elongation and high water permeability in the tonoplast (Peng et al., 2007; Sade et al., 2009; Wang et al., 2014). Conversely, it has been demonstrated that TIPs from Glycine soja (TIP2;1) and T. aestivum (TIP2;2) have a negative impact on A. thaliana drought tolerance (Wang et al., 2011; Xu et al., 2013a).

\section{ARBUSCULAR MYCORRHIZA IMPROVES WATER UPTAKE CAPACITY}

Increasing evidence indicates that arbuscular mycorrhiza (AM) play a crucial role in enhancing tolerance to drought (Abbaspour et al., 2012; Li et al., 2013, 2014; Barzana et al., 2014). Glomeromycota fungi are intimately associated with $80 \%$ of land plants; these organisms, supply water and nutrients to the roots of host plants in return for carbon compounds (Schmitz and Harrison, 2014). The improvement in water status is possible by harnessing the hyphae growing in the soil, enlarging the absorption surface, and exploiting the ability of the fungus to take up water despite the low soil water potential (Ruiz-Lozano etal., 2012). In addition, AM symbiosis affects the hydraulic properties of roots and maintains root water permeability by the regulating the expression of plant AQPs (PIPs and TIPs) and the activity of fungal AQPs (Li et al., 2013; Barzana et al., 2014). Considering the involvement of AM in plant response to drought stress, transport mechanisms play a crucial role in the establishment of plant-fungus interactions. The successful recognition of root-exuded plant metabolites, in particular flavonoids (F), 2-hydroxy fatty acids (2OH-FA), strigolactones (SL), and 16C cutin monomers, is a prerequisite for host-root colonization via hyphopodium development (Nadal and Paszkowski, 2013). Despite the importance of these transporters, the knowledge of this pre-symbiotic molecular crosstalk is limited. The isolation of the Petunia hybrida PDR1 transporter has shed light on SL transport, as it encodes for a putative root SL exporter (Kretzschmar etal., 2012). A corresponding protein has been found in the PM of hypodermal passage cells (HPC), the nonsuberized cortical entry points for AM hyphae (Kretzschmar et al., 2012). The entrance into cortical cells, where hyphae develop a treelike structure, is called an arbuscule. Arbuscules form through the PM and tonoplast invagination. Formed arbuscules are enveloped by a plant-derived periarbuscular membrane 
(PAM), a key symbiosis interface that contains several plant transporters and mediates bi-directional nutrient flux (Recorbet et al., 2013).

\section{OSMOTIC ADJUSTMENT AT THE CELLULAR LEVEL AS A FACET OF DROUGHT TOLERANCE}

Most plants have the capacity to tolerate low water content by increasing cellular osmolarity, thereby protecting cells from damage due to dehydration. This acclimating process involves the accumulation of an array of highly concentrated, osmotically active compounds in the cytosol, rather than in the vacuole, without the interference of primary metabolism. Osmotic regulators include inorganic ions and compatible solutes, such as sugars, sugar alcohols (polyols and cyclitols), amino acids [particularly proline (Pro)], and quaternary ammonium compounds (QACs), notably glycine betaine (GB; Sanders and Arndt, 2012). ABA participates in the accumulation of the aforementioned protectants. Therefore, ABA serves as a bridge between avoidance and tolerance responses. Strategies for achieving high levels of osmoregulatory solutes to cope with water deprivation are based either on altering metabolism or transport. Early studies indicated that the movement and differential distribution of these compounds, both within and between cells, is regulated by membrane-associated transporters; most of these transporters are secondary active transporters.

\section{AMINO ACIDS AND OACs TRANSPORTERS Proline transporters}

Proline accumulation is the first response of plants subjected to a range of environmental stressors, including drought. The correlation between this widely occurring amino acid and drought tolerance has been demonstrated in several plant species (Javed et al., 2014; Kumar et al., 2014a; Ravikumar et al., 2014; Singh et al., 2014). In addition to its well-established role in osmotic adjustment, Pro contributes to stress tolerance by functioning as a molecular chaperon that stabilizes subcellular structures, as a free radical scavenger and as stress-signaling molecule. During periods of stress, Pro is synthesized in the chloroplast and cytosol and then transported. Pro is degraded within root mitochondria (Szabados and Savoure, 2010) to provide energy, which beneficial for the accumulation of root biomass (Kavi Kishor and Sreenivasulu, 2013).

Transporters that recognize Pro have been classified into the following three subfamilies: (i) the amino acid permease (AAP) subfamily; (ii) the lysine-histidine transporter (LHT) subfamily; and (iii) the Pro transporter (ProT) subfamily. Members belonging to the AAP and LHT subfamilies are low selectivity proline transporters and participate in the translocation of neutral amino acids (Rentsch et al., 2007; Lehmann et al., 2010). Three ProTs have been identified in A. thaliana (Grallath etal., 2005). The expression profiles of the identified genes revealed that the ProT1 and ProT2 mRNA is accumulated when Pro levels are elevated. During progressive drought, only the ProT2 gene was strongly up-regulated. Grallath et al. (2005) observed that GUS expression driven by the ProT2 promoter occurred in the root epidermis and cortex. The corresponding protein has been found in the PM. AtProT2 exhibits Pro transport activity (Lehmann et al., 2011), and may facilitate Pro import across the PM under stress conditions (see Figure 4).

Transport mechanisms across chloroplast membranes, where Pro is synthesized, remain elusive. Two transport systems for Pro uptake into the mitochondria have been demonstrated (Di Martino et al., 2006). A study using Triticum durum seedlings confirmed that Pro enters the mitochondria through the uniporter (see Figure 4); in the mitochondria, Pro is further catabolized to glutamate (Glu). Glu is then exported from the mitochondria in exchange for Pro via the Pro/Glu antiporters (see Figure 4).

\section{Glycine betaine transporters}

Mass synthesis of GB occurs in response to water limitations and ABA treatment (Zhang et al., 2012). Comprehensive studies using transgenic plants such as Spinacia oleracea, S. lycopersicum, and $O$. sativa have demonstrated that GB accumulation results in improved plant tolerance to drought stress (Shirasawa et al., 2006; Zhang et al., 2011). The transport activity of GB has been demonstrated using ProTs from $A$. thaliana, Beta vulgaris, $H$. vulgare, $S$. lycopersicum, and Avicennia marina (Lehmann et al., 2011). The uptake of GB and Pro has been shown to be regulated by $\mathrm{pH}$ (Takabe, 2012).

\section{SUGAR AND SUGAR ALCOHOL TRANSPORTERS}

An increased synthesis of sugar and polyol compounds is triggered by various abiotic stresses. However, types of accumulated sugars may differ among plant species and nature of abiotic stressors (Zhuo et al., 2013; Folgado et al., 2014; Moyankova et al., 2014). Within the cell, carbohydrates are stored in chloroplasts and in the vacuole in the forms of starch and soluble sugars, respectively. In unfavorable conditions, the cytosolic concentrations of sugars and their derivatives are regulated by membraneembedded transporters. There are three major families of monoand disaccharide transporters, as follows: monosaccharide/polyol transporters (MST), sucrose transporters/carriers (SUT/SUC) and the SWEET sugar family of transporters (Lalonde and Frommer, 2012). The vast majority of sugar transport is an active process, requiring a proton motive force. However, recent findings indicate that sugar-specific facilitated diffusion transporters also exist in plant cells.

\section{Monosaccharide transporters}

Two tonoplast-localized, secondary transporters from A. thaliana are candidate vacuolar hexose loading proteins (see Figure 4). These transporters are TMT1 and TMT2 (Tonoplast Monosaccharide Transporters), which belong to the MST family. The expression of these proteins was up-regulated upon drought treatment. Mutation in the TMTs resulted in the decreased accumulation of glucose and fructose. The direct involvement of AtTMTs in energy-dependent vacuolar monosaccharide transport has been demonstrated in a glucose uptake assay using leaf mesophyll vacuoles isolated from wild-type and knockout lines (Wormit et al., 2006).

While the influx of hexoses into the vacuole is thermodynamically active, efflux is assumed to be a passive process. Efflux is mediated by members of the early responsive to dehydration 6like (ERD6) protein group, one of the clades within the MST 


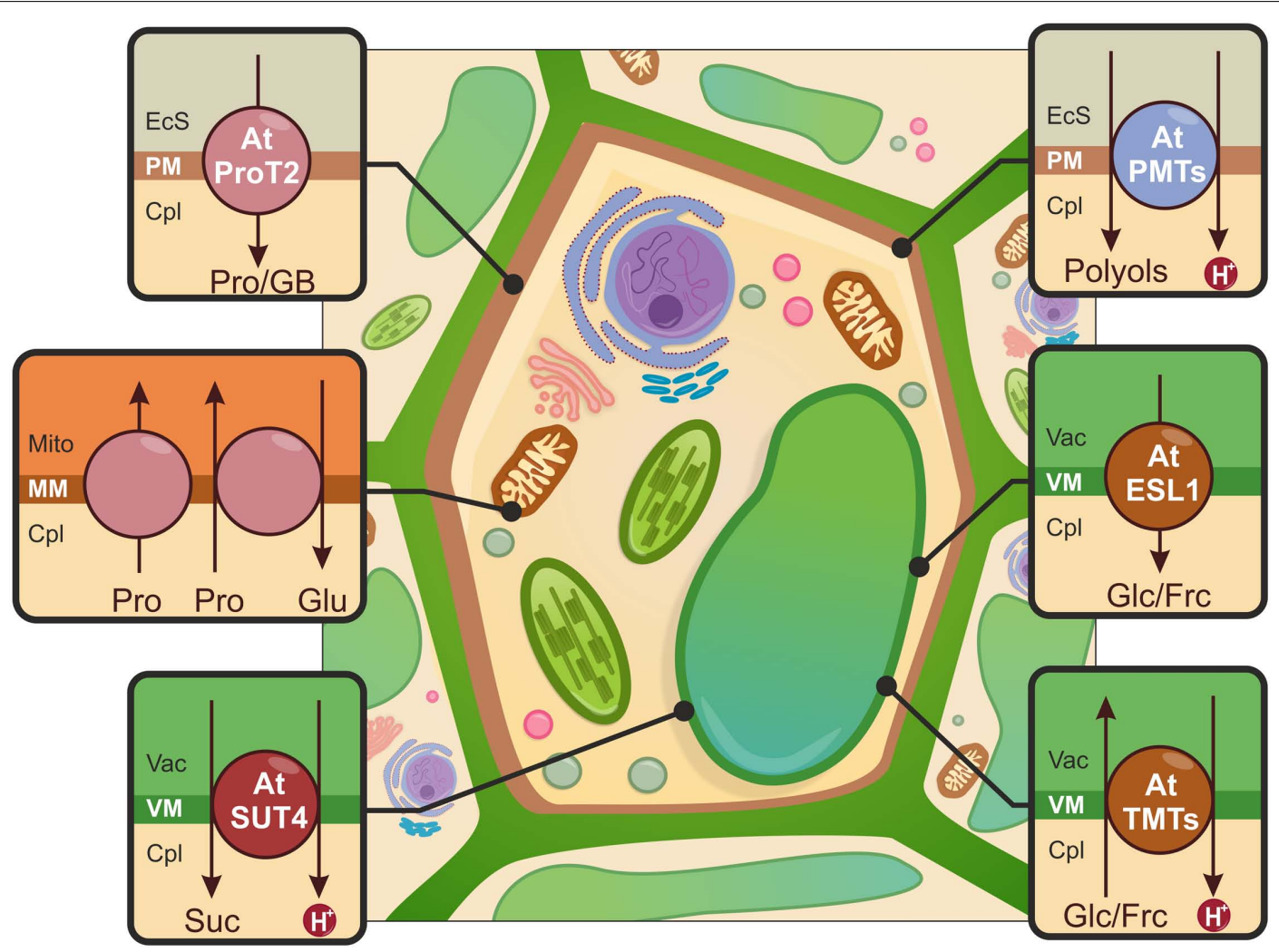

FIGURE 4 | Schematic illustration of the sub-cellular distribution of osmotically active compounds upon drought stress. Proline (Pro) and glycine betaine (GB) transport (pink) across the PM is mediated by Pro transporters (e.g., AtProT2). Pro translocation through the mitochondrial membrane $(\mathrm{MM})$ is possible due to Pro carriers that function as uniporters and Proline/Glutamate (Pro/Glu) antiporters. Glucose (Glc)/fructose (Frc) influx and efflux across the tonoplast (VM) is driven by Tonoplast
Monosaccharide Transporters (e.g., AtTMT1 and AtTMT2) and Early Responsive to Dehydration six-like 1 carrier (AtESL1), indicated in brown. Sucrose (Suc) transporters (e.g., AtSUT4, red) participate in Suc export from the vacuole. The import of polyols into the cell is possible due to polyol/monosaccharide transporters (e.g., AtPMT1, AtPMT2, AtPMT5), shown in blue. EcS, extracellular space; Cpl, cytoplasm; Mito, mitochondria; Vac, vacuole. family. Three members have been characterized thus far; only two have been described in the context of drought stress (Yamada et al., 2010; Poschet et al., 2011). The first identified gene, ERD6, was isolated from a cDNA library obtained from $A$. thaliana plants subjected to water deprivation (Kiyosue et al., 1998). Further phylogenetic analysis of the ERD6-like family revealed a close homologue of ERD6, the tonoplast-localized ESL1 (ERD six-like 1; see Figure 4; Yamada et al., 2010). The accumulation of AtESL1 mRNA was observed after drought and the exogenous application of ABA. GUS staining was detected mainly in pericycle and xylem parenchyma cells of roots. To obtain direct evidence that AtESL1 is a functional monosaccharide transporter, a heterologous expression system in BY-2 cells was used. Translocation ability was not altered by a reduction in the proton gradient, indicating that ESL1 acts as a facilitated diffusion carrier (Yamada et al., 2010).

\section{Disaccharide transporters}

Our understanding of the involvement of SUT in drought tolerance is limited. Among several described SUTs, only one transporter from $P$. tremula (PtaSUT4), one from O. sativa (OsSUT2) and two from A. thaliana (AtSUC2 and AtSUC4), may be relevant in a drought tolerance context; these proteins are tonoplast symporters. PtaSUT4 is predominantly present in the tonoplast of mesophyll cells in stems and source leaves (Payyavula et al., 2011). RNAi-mediated silencing of PtaSUT4 resulted in the increased vacuolar sequestration of SUC; this promoted leaf growth and reduced of water uptake and movement in the xylem. Simultaneously, concentration of raffinose family oligosaccharides (RFOs) has also been reduced, implying the role of PtaSUT4 in regulation of osmotic gradients between cellular compartments in response to water stress (Frost et al., 2012). RFOs serve as compatible solutes for protection against abiotic stresses especially drought (Taji et al., 2002), and are synthesized in the cytosol mainly from sucrose (den Ende, 2013). Therefore, suppression of PtaSUT4 caused a decline in cytosolic sucrose pool necessary for RFOs biosynthesis upon stress conditions. The SUT protein from O. sativa (OsSUT2) is a tonoplast-localized $\mathrm{H}^{+}$-Suc symporter (Eom et al., 2011). GUS activity was detectable in all of the examined $O$. sativa tissues, the highest OsSUT2 expression was observed in leaf mesophyll cells. In an analysis of primary carbon metabolites, an increased accumulation of Suc in the leaves of ossut 2 mutant plants was observed; this might be the result of decreased sugar export activity in the vacuole. Changes in OsSUT2 expression upon drought treatment 
have not been observed (Eom et al., 2011). In a parallel study, Ibraheem etal. (2011) demonstrated the strong up-regulation of OsSUT2 during water stress. Two A. thaliana SUT proteins involved in the drought stress response have been identified (Gong et al., 2014). The loss-of-function mutant lines for AtSUC2 and AtSUC4 displayed hypersensitivity to drought and ABA treatment; this was due to changes in sucrose distribution in the shoots and roots and to sucrose accumulation in source organs. In response to drought and ABA treatment, AtSUT4 and AtSUT2 expression was induced in the minor veins of leaves where high-capacity sucrose transport is needed for phloem loading (Gong et al., 2014). The heterologous expression of AtSUC4 in yeast confirmed Suc transport ability (see Figure 4; Weise et al., 2000). Overall, the results suggest a putative role for AtSUC2 and AtSUC4 in Suc flux under drought stress conditions.

\section{Sugar alcohol transporters}

Six genes belonging to the polyol/monosaccharide transporter (PMT) subfamily have been identified in A. thaliana; these belong to the MST family. However, only AtPMT5, AtPMT1, and AtPMT2 have been partially characterized (see Figure 4; Klepek et al., 2005, 2010; Reinders etal., 2005). Simultaneous analyses of AtPMT5 described this protein as a broad-spectrum $\mathrm{H}^{+}$symporter for polyols, cyclitols and numerous monosaccharides that resides in the PM (Klepek et al., 2005; Reinders et al., 2005). Considering its wide substrate specificity, a ubiquitous expression pattern and an unchanged mutant phenotype under testing conditions (e.g., drought), the physiological functions of AtPMT5 remain unclear and require further investigation (Klepek et al., 2005). AtPMT1 and AtPMT2 catalyze the energy-dependent PM transport of xylitol and fructose in pollen grains and young xylem; these proteins may also play a role in plant CW modifications (Klepek et al., 2010).

\section{CONCLUSION}

It is predicted that water deficits will continue to be a major abiotic factor affecting global crop yields. Genetic engineering for drought resistance using reported candidate genes in major food crops is in progress.

Recent discoveries in plant transporters, e.g., the coordinated action of ABA exporters and importers that control the stomatal pore, points directly toward candidate genes that may have innovative applications. However, the underlying message from basic research is that many fundamental mechanisms influencing drought adaptation remain to be uncovered. The existence of homologs from multigenic families (e.g., ABC proteins) and spliced isoforms (e.g., ZIFL1) illustrate that molecular transport can have various local tissue/organ effects that result in coordinated plant adaptation to drought stress. Understanding the complexity of such responses will be the main challenge in upcoming years.

The knowledge acquired must be adapted to particular evolutionary backgrounds. For legumes (the second most important family of crop plants after Poaceae), targeting drought tolerance via the genetic manipulation of a particular organ (e.g., root) during especially susceptible stages such as nodulation could be important. However, the legume-specific reactions of roots to ABA, combined with nodulation control and environmental status, force researchers to propose new legume-specific approaches. It is expected that the research into the fundamental mechanisms of plant membrane transport processes will continue. New crop varieties will be produced, and new avenues toward more sustainable and productive agriculture will open up, in spite of the impending challenges.

\section{ACKNOWLEDGMENT}

National Science Centre Grants supported this work: 2013/10/M/ NZ3/00260.

\section{REFERENCES}

Abbaspour, H., Saeidi-Sar, S., Afshari, H., and Abdel-Wahhab, M. A. (2012). Tolerance of mycorrhiza infected pistachio (Pistacia vera L.) seedling to drought stress under glasshouse conditions. J. Plant Physiol. 169, 704-709. doi: 10.1016/j.jplph.2012.01.014

Andres, Z., Perez-Hormaeche, J., Leidi, E. O., Schlucking, K., Steinhorst, L., Mclachlan, D. H., et al. (2014). Control of vacuolar dynamics and regulation of stomatal aperture by tonoplast potassium uptake. Proc. Natl. Acad. Sci. U.S.A. 111, E1806-E1814. doi: 10.1073/pnas.1320421111

Arif, A., Zafar, Y., Arif, M., and Blumwald, E. (2013). Improved growth, drought tolerance, and ultrastructural evidence of increased turgidity in tobacco plants overexpressing Arabidopsis vacuolar pyrophosphatase (AVP1). Mol. Biotechnol. 54, 379-392. doi: 10.1007/s12033-012-9577-9579

Aroca, R., Porcel, R., and Ruiz-Lozano, J. M. (2012). Regulation of root water uptake under abiotic stress conditions. J. Exp. Bot. 63, 43-57. doi: 10.1093/jxb/err266

Aroca, R., and Ruiz-Lozano, J. (2012). "Regulation of root water uptake under drought stress conditions," in Plant Responses to Drought Stress, ed. R. Aroca (Berlin: Springer), 113-127. doi: 10.1007/978-3-642-32653-0_4

Bacelar, E. V. A., Moutinho-Pereira, J., Gonçalves, B. C., Brito, C. Q., GomesLaranjo, J., Ferreira, H. F., et al. (2012). "Water use strategies of plants under drought conditions," in Plant Responses to Drought Stress, ed. R. Aroca (Berlin: Springer), 145-170. doi: 10.1007/978-3-642-32653-0_6

Barzana, G., Aroca, R., Bienert, G. P., Chaumont, F., and Ruiz-Lozano, J. M. (2014). New insights into the regulation of aquaporins by the arbuscular mycorrhizal symbiosis in maize plants under drought stress and possible implications for plant performance. Mol. Plant Microbe Interact. 27, 349-363. doi: 10.1094/MPMI-0913-0268-R

Bauer, H., Ache, P., Lautner, S., Fromm, J., Hartung, W., Al-Rasheid, K. A., et al. (2013). The stomatal response to reduced relative humidity requires guard cell-autonomous ABA synthesis. Curr. Biol. 23, 53-57. doi: 10.1016/j.cub.2012. 11.022

Becker, D., Hoth, S., Ache, P., Wenkel, S., Roelfsema, M. R., Meyerhoff, O., et al. (2003). Regulation of the ABA-sensitive Arabidopsis potassium channel gene GORK in response to water stress. FEBS Lett. 554, 119-126. doi: 10.1016/S0014-5793(03)01118-9

Bessire, M., Borel, S., Fabre, G., Carraca, L., Efremova, N., Yephremov, A., et al. (2011). A member of the PLEIOTROPIC DRUG RESISTANCE family of ATP binding cassette transporters is required for the formation of a functional cuticle in Arabidopsis. Plant Cell 23, 1958-1970. doi: 10.1105/tpc.111.083121

Bird, D., Beisson, F., Brigham, A., Shin, J., Greer, S., Jetter, R., et al. (2007). Characterization of Arabidopsis ABCG11/WBC11, an ATP binding cassette (ABC) transporter that is required for cuticular lipid secretion. Plant J. 52, 485-498. doi: 10.1111/j.1365-313X.2007.03252.x

Boursiac, Y., Leran, S., Corratge-Faillie, C., Gojon, A., Krouk, G., and Lacombe, B. (2013). ABA transport and transporters. Trends Plant Sci. 18, 325-333. doi: 10.1016/j.tplants.2013.01.007

Buda, G. J., Barnes, W. J., Fich, E. A., Park, S., Yeats, T. H., Zhao, L., et al. (2013). An ATP binding cassette transporter is required for cuticular wax deposition and desiccation tolerance in the moss physcomitrella patens. Plant Cell. 25, 40004013. doi: 10.1105/tpc.113.117648

Burla, B., Pfrunder, S., Nagy, R., Francisco, R. M., Lee, Y., and Martinoia, E. (2013). Vacuolar transport of abscisic acid glucosyl ester is mediated by ATP-binding cassette and proton-antiport mechanisms in Arabidopsis. Plant Physiol. 163, 14461458. doi: 10.1104/pp.113.222547 
Chaumont, F., and Tyerman, S. D. (2014). Aquaporins: highly regulated channels controlling plant water relations. Plant Physiol. 164, 1600-1618. doi: 10.1104/pp.113.233791

Chen, G., Komatsuda, T., Ma, J. F., Nawrath, C., Pourkheirandish, M., Tagiri, A., et al. (2011). An ATP-binding cassette subfamily G full transporter is essential for the retention of leaf water in both wild barley and rice. Proc. Natl. Acad. Sci U.S.A. 108, 12354-12359. doi: 10.1073/pnas.1108444108

Cho, D., Kim, S. A., Murata, Y., Lee, S., Jae, S. K., Nam, H. G., et al. (2009). De-regulated expression of the plant glutamate receptor homolog AtGLR3.1 impairs long-term $\mathrm{Ca}^{2+}$-programmed stomatal closure. Plant J. 58, 437-449. doi: 10.1111/j.1365-313X.2009.03789.x

Choi, H., Jin, J. Y., Choi, S., Hwang, J. U., Kim, Y. Y., Suh, M. C., et al. (2011). An ABCG/WBC-type ABC transporter is essential for transport of sporopollenin precursors for exine formation in developing pollen. Plant J. 65, 181-193. doi: 10.1111/j.1365-313X.2010.04412.x

Choi, H., Ohyama, K., Kim, Y. Y., Jin, J. Y., Lee, S. B., Yamaoka, Y., et al. (2014). The role of Arabidopsis ABCG9 and ABCG31 ATP binding cassette transporters in pollen fitness and the deposition of steryl glycosides on the pollen coat. Plant Cell 26, 310-324. doi: 10.1105/tpc.113.118935

Cui, X. H., Hao, F. S., Chen, H., Chen, J., and Wang, X. C. (2008). Expression of the Vicia faba VfPIP1 gene in Arabidopsis thaliana plants improves their drought resistance. J. Plant Res. 121, 207-214. doi: 10.1007/s10265-007-0130-Z

De Angeli, A., Zhang, J., Meyer, S., and Martinoia, E. (2013). AtALMT9 is a malateactivated vacuolar chloride channel required for stomatal opening in Arabidopsis. Nat. Commun. 4, 1804. doi: 10.1038/ncomms 2815

Debono, A., Yeats, T. H., Rose, J. K., Bird, D., Jetter, R., Kunst, L., et al. (2009). Arabidopsis LTPG is a glycosylphosphatidylinositol-anchored lipid transfer protein required for export of lipids to the plant surface. Plant Cell 21, 1230-1238. doi: 10.1105/tpc.108.064451

den Ende, W. V. (2013). Multifunctional fructans and raffinose family oligosaccharides. Front. Plant Sci. 4:247. doi: 10.3389/fpls.2013.00247

Di Martino, C., Pizzuto, R., Pallotta, M. L., De Santis, A., and Passarella, S. (2006). Mitochondrial transport in proline catabolism in plants: the existence of two separate translocators in mitochondria isolated from durum wheat seedlings. Planta 223, 1123-1133. doi: 10.1007/s00425-005-0 166-Z

Ding, Y., and Oldroyd, G. E. (2009). Positioning the nodule, the hormone dictum. Plant Signal. Behav. 4, 89-93. doi: 10.4161/psb.4.2.7693

Dou, X.-Y., Yang, K.-Z., Zhang, Y., Wang, W., Liu, X.-L., Chen, L.-Q., et al. (2011). WBC27, an adenosine Tri-phosphate-binding cassette protein, controls pollen wall formation and patterning in Arabidopsis. J. Integr. Plant Biol. 53, 74-88. doi: 10.1111/j.1744-7909.2010.01010.x

Dubovskaya, L. V., Bakakina, Y. S., Kolesneva, E. V., Sodel, D. L., Mcainsh, M. R., Hetherington, A. M., et al. (2011). cGMP-dependent ABA-induced stomatal closure in the ABA-insensitive Arabidopsis mutant abi1-1. New Phytol. 191, 57-69. doi: 10.1111/j.1469-8137.2011.03661.x

Eisenach, C., Papanatsiou, M., Hillert, E.-K., and Blatt, M. R. (2014). Clustering of the $\mathrm{K}^{+}$channel GORK of Arabidopsis parallels its gating by extracellular $\mathrm{K}^{+}$. Plant J. 78, 203-214. doi: 10.1111/tpj.12471

Eom, J. S., Cho, J. I., Reinders, A., Lee, S. W., Yoo, Y., Tuan, P. Q., et al. (2011) Impaired function of the tonoplast-localized sucrose transporter in rice, OsSUT2, limits the transport of vacuolar reserve sucrose and affects plant growth. Plant Physiol. 157, 109-119. doi: 10.1104/pp.111.176982

Ernst, L., Goodger, J. Q., Alvarez, S., Marsh, E. L., Berla, B., Lockhart, E., et al. (2010). Sulphate as a xylem-borne chemical signal precedes the expression of ABA biosynthetic genes in maize roots. J. Exp. Bot. 61, 3395-3405. doi: $10.1093 /$ jxb/erq160

Farooq, M., Wahid, A., Kobayashi, N., Fujita, D., and Basra, S. M. A. (2009). Plant drought stress: effects, mechanisms and management. Agron. Sustain. Dev. 29, 185-212. doi: 10.1051/agro:2008021

Finkelstein, R. (2013). Abscisic acid synthesis and response. Arabidopsis Book 11, e0166. doi: 10.1199/tab.0166

Folgado, R., Sergeant, K., Renaut, J., Swennen, R., Hausman, J. F., and Panis, B. (2014). Changes in sugar content and proteome of potato in response to cold and dehydration stress and their implications for cryopreservation. J. Proteom. 98, 99-111. doi: 10.1016/j.jprot.2013.11.027

Frost, C. J., Nyamdari, B., Tsai, C. J., and Harding, S. A. (2012). The tonoplastlocalized sucrose transporter in Populus (PtaSUT4) regulates whole-plant water relations, responses to water stress, and photosynthesis. PLoS ONE 7:e44467. doi: 10.1371/journal.pone.0044467

Geiger, D., Maierhofer, T., Al-Rasheid, K. A., Scherzer, S., Mumm, P., Liese, A., et al. (2011). Stomatal closure by fast abscisic acid signaling is mediated by the guard cell anion channel SLAH3 and the receptor RCAR1. Sci. Signal. 4, ra32. doi: 10.1126/scisignal.2001346

Geiger, D., Scherzer, S., Mumm, P., Stange, A., Marten, I., Bauer, H., et al. (2009). Activity of guard cell anion channel SLAC1 is controlled by drought-stress signaling kinase-phosphatase pair. Proc. Natl. Acad. Sci. U.S.A. 106, 21425-21430. doi: 10.1073/pnas.0912021106

Gobert, A., Isayenkov, S., Voelker, C., Czempinski, K., and Maathuis, F. J. (2007). The two-pore channel TPK1 gene encodes the vacuolar $\mathrm{K}^{+}$conductance and plays a role in $\mathrm{K}^{+}$homeostasis. Proc. Natl. Acad. Sci. U.S.A. 104, 10726-10731. doi: 10.1073/pnas.0702595104

Gong, X., Liu, M., Zhang, L., Ruan, Y., Ding, R., Ji, Y., et al. (2014). Arabidopsis AtSUC2 and AtSUC4, encoding sucrose transporters, are required for abiotic stress tolerance in an ABA-dependent pathway. Physiol. Plant. doi: 10.1111/ppl.12225 [Epub ahead of print].

Goodger, J. Q., and Schachtman, D. P. (2010). Re-examining the role of ABA as the primary long-distance signal produced by water-stressed roots. Plant Signal. Behav. 5, 1298-1301. doi: 10.4161/psb.5.10.13101

Grallath, S., Weimar, T., Meyer, A., Gumy, C., Suter-Grotemeyer, M., Neuhaus, J. M., etal. (2005). The AtProT family. Compatible solute transporters with similar substrate specificity but differential expression patterns. Plant Physiol. 137, 117-126. doi: 10.1104/pp.104.055079

Guo, F. Q., Young, J., and Crawford, N. M. (2003). The nitrate transporter AtNRT1.1 (CHL1) functions in stomatal opening and contributes to drought susceptibility in Arabidopsis. Plant Cell 15, 107-117. doi: 10.1105/tpc.006312

Heinen, R. B., Bienert, G. P., Cohen, D., Chevalier, A. S., Uehlein, N., Hachez, C., et al. (2014). Expression and characterization of plasma membrane aquaporins in stomatal complexes of Zea mays. Plant Mol. Biol. 86, 335-350. doi: 10.1007/s11103-014-0232-7

Heinen, R. B., Ye, Q., and Chaumont, F. (2009). Role of aquaporins in leaf physiology. J. Exp. Bot. 60, 2971-2985. doi: 10.1093/jxb/erp171

Hosy, E., Vavasseur, A., Mouline, K., Dreyer, I., Gaymard, F., Poree, F., et al. (2003). The Arabidopsis outward $\mathrm{K}^{+}$channel GORK is involved in regulation of stomatal movements and plant transpiration. Proc. Natl. Acad. Sci. U.S.A. 100, 5549-5554. doi: 10.1073/pnas.0733970100

Ibraheem, O., Dealtry, G., Roux, S., and Bradley, G. (2011). The effect of drought and salinity on the expressional levels of sucrose transporters in rice ('Oryza sativa' Nipponbare) cultivar plants. Plant Omics 4, 68-74.

Islam, M. M., Munemasa, S., Hossain, M. A., Nakamura, Y., Mori, I. C., and Murata, Y. (2010). Roles of AtTPC1, vacuolar two pore channel 1, in Arabidopsis stomatal closure. Plant Cell Physiol. 51, 302-311. doi: 10.1093/pcp/pcq001

Jang, J. Y., Kim, D. G., Kim, Y. O., Kim, J. S., and Kang, H. (2004). An expression analysis of a gene family encoding plasma membrane aquaporins in response to abiotic stresses in Arabidopsis thaliana. Plant Mol. Biol. 54, 713-725. doi: 10.1023/B:PLAN.0000040900.61345.a6

Jang, J. Y., Lee, S. H., Rhee, J. Y., Chung, G. C., Ahn, S. J., and Kang, H. (2007). Transgenic Arabidopsis and tobacco plants overexpressing an aquaporin respond differently to various abiotic stresses. Plant. Mol. Biol. 64, 621-632. doi: 10.1007/s11103-007-9181-8

Javed, S., Ashraf, M. Y., Meraj, M., Bukhari, S. A., and Zovia, I. (2014). Salinity and drought induced antioxidant responses in different cultivars of safflower (Carthamus tinctorius L.). Curr. Pharm. Biotechnol. 14, 814-819. doi: $10.2174 / 1389201014666131227114228$

Jossier, M., Kroniewicz, L., Dalmas, F., Le Thiec, D., Ephritikhine, G., Thomine, S., et al. (2010). The Arabidopsis vacuolar anion transporter, AtCLCc, is involved in the regulation of stomatal movements and contributes to salt tolerance. Plant J. 64, 563-576. doi: 10.1111/j.1365-313X.2010.04352.x

Kang, J., Hwang, J., Lee, M., Kim, Y., Assmann, S., Martinoia, E., et al. (2010). PDR-type ABC transporter mediates cellular uptake of the phytohormone abscisic acid. Proc. Natl. Acad. Sci. U.S.A. 107, 2355-2360. doi: 10.1073/pnas. 0909222107

Kanno, Y., Hanada, A., Chiba, Y., Ichikawa, T., Nakazawa, M., Matsui, M., et al. (2012). Identification of an abscisic acid transporter by functional screening using the receptor complex as a sensor. Proc. Natl. Acad. Sci. U.S.A. 109, 9653-9658. doi: 10.1073/pnas. 1203567109 
Kavi Kishor, P. B., and Sreenivasulu, N. (2013). Is proline accumulation per se correlated with stress tolerance or is proline homeostasis a more critical issue? Plant Cell Environ. 37, 300-311. doi: 10.1111/pce.12157

Kim, H., Lee, S. B., Kim, H. J., Min, M. K., Hwang, I., and Suh, M. C. (2012). Characterization of glycosylphosphatidylinositol-anchored lipid transfer protein 2 (LTPG2) and overlapping function between LTPG/LTPG1 and LTPG2 in cuticular wax export or accumulation in Arabidopsis thaliana. Plant Cell Physiol. 53, 1391-1403. doi: 10.1093/pcp/pcs083

Kim, T. H., Bohmer, M., Hu, H., Nishimura, N., and Schroeder, J. I. (2010). Guard cell signal transduction network: advances in understanding abscisic acid, $\mathrm{CO}_{2}$, and $\mathrm{Ca}^{2+}$ signaling. Annu. Rev. Plant Biol. 61, 561-591. doi: 10.1146/annurevarplant-042809-112226

Kiyosue, T., Abe, H., Yamaguchi-Shinozaki, K., and Shinozaki, K. (1998). ERD6, a cDNA clone for an early dehydration-induced gene of Arabidopsis, encodes a putative sugar transporter. Biochim. Biophys. Acta 1370, 187-191. doi: 10.1016/S0005-2736(98)00007-8

Klein, M., Geisler, M., Suh, S. J., Kolukisaoglu, H. U., Azevedo, L., Plaza, S., et al. (2004). Disruption of AtMRP4, a guard cell plasma membrane ABCC-type ABC transporter, leads to deregulation of stomatal opening and increased drought susceptibility. Plant J. 39, 219-236. doi: 10.1111/j.1365-313X.2004.02125.x

Klepek, Y. S., Geiger, D., Stadler, R., Klebl, F., Landouar-Arsivaud, L., Lemoine, R., et al. (2005). Arabidopsis POLYOL TRANSPORTER5, a new member of the monosaccharide transporter-like superfamily, mediates $\mathrm{H}^{+}$-Symport of numerous substrates, including myo-inositol, glycerol, and ribose. Plant Cell 17, 204-218. doi: 10.1105/tpc.104.026641

Klepek, Y. S., Volke, M., Konrad, K. R., Wippel, K., Hoth, S., Hedrich, R., et al. (2010). Arabidopsis thaliana POLYOL/MONOSACCHARIDE TRANSPORTERS 1 and 2: fructose and xylitol/H+ symporters in pollen and young xylem cells. J. Exp. Bot. 61, 537-550. doi: 10.1093/jxb/erp322

Kosma, D. K., Bourdenx, B., Bernard, A., Parsons, E. P., Lu, S., Joubes, J., et al. (2009). The impact of water deficiency on leaf cuticle lipids of Arabidopsis. Plant Physiol. 151, 1918-1929. doi: 10.1104/pp.109.141911

Kretzschmar, T., Kohlen, W., Sasse, J., Borghi, L., Schlegel, M., Bachelier, J. B., et al. (2012). A petunia ABC protein controls strigolactone-dependent symbiotic signalling and branching. Nature 483, 341-344. doi: 10.1038/nature 10873

Kudoyarova, G., Veselova, S., Hartung, W., Farhutdinov, R., Veselov, D., and Sharipova, G. (2011). Involvement of root ABA and hydraulic conductivity in the control of water relations in wheat plants exposed to increased evaporative demand. Planta 233, 87-94. doi: 10.1007/s00425-010-1286-1287

Kumar, D., Datta, R., Sinha, R., Ghosh, A., and Chattopadhyay, S. (2014a). Proteomic profiling of gamma-ECS overexpressed transgenic Nicotiana in response to drought stress. Plant Signal. Behav. 9. [Epub ahead of print].

Kumar, T., Uzma, Khan, M. R., Abbas, Z., and Ali, G. M. (2014b). Genetic improvement of sugarcane for drought and salinity stress tolerance using arabidopsis vacuolar pyrophosphatase (AVP1) gene. Mol. Biotechnol. 56, 199-209. doi: 10.1007/s12033-013-9695-z

Kuromori, T., Miyaji, T., Yabuuchi, H., Shimizu, H., Sugimoto, E., and Kamiya, A. (2010). ABC transporter AtABCG25 is involved in abscisic acid transport and responses. Proc. Natl. Acad. Sci. U.S.A. 107, 2361-2366. doi: 10.1073/pnas.0912516107

Kuromori, T., Sugimoto, E., and Shinozaki, K. (2011). Arabidopsis mutants of AtABCG22, an ABC transporter gene, increase water transpiration and drought susceptibility. Plant J. 67, 885-894. doi: 10.1111/j.1365-313X.2011.04641.x

Lalonde, S., and Frommer, W. B. (2012). SUT sucrose and MST monosaccharide transporter inventory of the Selaginella genome. Front. Plant Sci. 3:24. doi 10.3389/fpls.2012.00024

Landgraf, R., Smolka, U., Altmann, S., Eschen-Lippold, L., Senning, M., Sonnewald, S., et al. (2014). The ABC transporter ABCG1 Is required for suberin formation in potato tuber periderm. Plant Cell 26, 3403-3415. doi: 10.1105/tpc.114.124776

Lawson, T., and Blatt, M. R. (2014). Stomatal size, speed, and responsiveness impact on photosynthesis and water use efficiency. Plant Physiol. 164, 1556-1570. doi: 10.1104/pp.114.237107

Lee, K. H., Piao, H. L., Kim, H.-Y., Choi, S. M., Jiang, F., Hartung, W., et al. (2006). Activation of glucosidase via stress-induced polymerization rapidly increases active pools of abscisic acid. Cell 126, 1109-1120. doi: 10.1016/j.cell.2006.07.034

Lee, M., Choi, Y., Burla, B., Kim, Y. Y., Jeon, B., Maeshima, M., et al. (2008). The ABC transporter AtABCB14 is a malate importer and modulates stomatal response to $\mathrm{CO}_{2}$. Nat. Cell Biol. 10, 1217-1223. doi: 10.1038/ncb1782
Lee, S. B., Go, Y. S., Bae, H. J., Park, J. H., Cho, S. H., Cho, H. J., et al. (2009a). Disruption of glycosylphosphatidylinositol-anchored lipid transfer protein gene altered cuticular lipid composition, increased plastoglobules, and enhanced susceptibility to infection by the fungal pathogen Alternaria brassicicola. Plant Physiol. 150, 42-54. doi: 10.1104/pp.109.137745

Lee, S. C., Lan, W., Buchanan, B. B., and Luan, S. (2009b). A protein kinasephosphatase pair interacts with an ion channel to regulate ABA signaling in plant guard cells. Proc. Natl. Acad. Sci. U.S.A. 106, 21419-21424. doi: 10.1073/pnas.0910601106

Lehmann, S., Funck, D., Szabados, L., and Rentsch, D. (2010). Proline metabolism and transport in plant development. Amino Acids 39, 949-962. doi: 10.1007/s00726-010-0525-523

Lehmann, S., Gumy, C., Blatter, E., Boeffel, S., Fricke, W., and Rentsch, D. (2011). In planta function of compatible solute transporters of the AtProT family. J. Exp. Bot. 62, 787-796. doi: 10.1093/jxb/erq320

Li-Beisson, Y., Shorrosh, B., Beisson, F., Andersson, M. X., Arondel, V., Bates, P. D., et al. (2010). Acyl-lipid metabolism. Arabidopsis Book 8, e0133. doi: $10.1199 /$ tab.0133

Li, T., Hu, Y. J., Hao, Z. P., Li, H., and Chen, B. D. (2013). Aquaporin genes GintAQPF1 and GintAQPF2 from Glomus intraradices contribute to plant drought tolerance. Plant Signal. Behav. 8, e24030. doi: 10.4161/psb.24030

Li, T., Lin, G., Zhang, X., Chen, Y., Zhang, S., and Chen, B. (2014). Relative importance of an arbuscular mycorrhizal fungus (Rhizophagus intraradices) and root hairs in plant drought tolerance. Mycorrhiza 24, 595-602. doi: 10.1007/s00572-014-0578-3

Liang, Y., Mitchell, D. M., and Harris, J. M. (2007). Abscisic acid rescues the root meristem defects of the Medicago truncatula latd mutant. Dev. Biol. 304, 297-307. doi: 10.1016/j.ydbio.2006.12.037

Lobet, G., Couvreur, V., Meunier, F., Javaux, M., and Draye, X. (2014). Plant water uptake in drying soils. Plant Physiol. 164, 1619-1627. doi: 10.1104/pp.113.233486

Luo, B., Xue, X. Y., Hu, W. L., Wang, L. J., and Chen, X. Y. (2007). An ABC transporter gene of Arabidopsis thaliana, AtWBC11, is involved in cuticle development and prevention of organ fusion. Plant Cell Physiol. 48, 1790-1802. doi: $10.1093 / \mathrm{pcp} / \mathrm{pcm} 152$

Mahdieh, M., Mostajeran, A., Horie, T., and Katsuhara, M. (2008). Drought stress alters water relations and expression of PIP-type aquaporin genes in Nicotiana tabacum plants. Plant Cell Physiol. 49, 801-813. doi: 10.1093/pcp/pcn 054

Maierhofer, T., Diekmann, M., Offenborn, J. N., Lind, C., Bauer, H., Hashimoto, K., et al. (2014). Site- and kinase-specific phosphorylation-mediated activation of SLAC1, a guard cell anion channel stimulated by abscisic acid. Sci. Signal. 7, ra86. doi: 10.1126/scisignal.2005703

Maurel, C., Verdoucq, L., Luu, D. T., and Santoni, V. (2008). Plant aquaporins: membrane channels with multiple integrated functions. Annu. Rev. Plant Biol. 59, 595-624. doi: 10.1146/annurev.arplant.59.032607.092734

McAdam, S. A., and Brodribb, T. J. (2014). Separating active and passive influences on stomatal control of transpiration. Plant Physiol. 164, 1578-1586. doi: 10.1104/pp.113.231944

McFarlane, H. E., Shin, J. J., Bird, D. A., and Samuels, A. L. (2010). Arabidopsis ABCG transporters, which are required for export of diverse cuticular lipids, dimerize in different combinations. Plant Cell 22, 3066-3075. doi: 10.1105/tpc.110.077974

McFarlane, H. E., Watanabe, Y., Yang, W., Huang, Y., Ohlrogge, J., and Samuels, A. L. (2014). Golgi- and trans-Golgi network-mediated vesicle trafficking is required for wax secretion from epidermal cells. Plant Physiol. 164, 1250-1260. doi: 10.1104/pp.113.234583

Meyer, S., Mumm, P., Imes, D., Endler, A., Weder, B., Al-Rasheid, K. A., et al. (2010). AtALMT12 represents an R-type anion channel required for stomatal movement in Arabidopsis guard cells. Plant J. 63, 1054-1062. doi: 10.1111/j.1365313X.2010.04302.x

Moshelion, M., Halperin, O., Wallach, R., Oren, R., and Way, D. A. (2014). Role of aquaporins in determining transpiration and photosynthesis in water-stressed plants: crop water-use efficiency, growth and yield. Plant Cell Environ. doi: 10.1111/pce.12410 [Epub ahead of print].

Moyankova, D., Mladenov, P., Berkov, S., Peshev, D., Georgieva, D., and Djilianov, D. (2014). Metabolic profiling of the resurrection plant Haberlea rhodopensis during desiccation and recovery. Physiol. Plant. 152, 675-687. doi: 10.1111/ppl.12212

Nadal, M., and Paszkowski, U. (2013). Polyphony in the rhizosphere: presymbiotic communication in arbuscular mycorrhizal symbiosis. Curr. Opin. Plant Biol. 16, 473-479. doi: 10.1016/j.pbi.2013.06.005 
Nagy, R., Grob, H., Weder, B., Green, P., Klein, M., Frelet-Barrand, A., et al. (2009). The Arabidopsis ATP-binding cassette protein AtMRP5/AtABCC5 is a high affinity inositol hexakisphosphate transporter involved in guard cell signaling and phytate storage. J. Biol. Chem. 284, 33614-33622. doi: 10.1074/jbc.M109.030247

Negi, J., Matsuda, O., Nagasawa, T., Oba, Y., Takahashi, H., Kawai-Yamada, M., et al. (2008). $\mathrm{CO}_{2}$ regulator SLAC1 and its homologues are essential for anion homeostasis in plant cells. Nature 452, 483-486. doi: 10.1038/nature06720

Osakabe, Y., Arinaga, N., Umezawa, T., Katsura, S., Nagamachi, K., Tanaka, H., et al. (2013). Osmotic stress responses and plant growth controlled by potassium transporters in Arabidopsis. Plant Cell 25, 609-624. doi: 10.1105/tpc.112.1 05700

Osakabe, Y., Yamaguchi-Shinozaki, K., Shinozaki, K., and Tran, L. S. (2014). ABA control of plant macroelement membrane transport systems in response to water deficit and high salinity. New Phytol. 202, 35-49. doi: 10.1111/nph.12613

Padmanaban, S., Chanroj, S., Kwak, J. M., Li, X., Ward, J. M., and Sze, H. (2007). Participation of endomembrane cation $/ \mathrm{H}^{+}$exchanger AtCHX20 in osmoregulation of guard cells. Plant Physiol. 144, 82-93. doi: 10.1104/pp.106.092155

Panikashvili, D., Savaldi-Goldstein, S., Mandel, T., Yifhar, T., Franke, R. B., Hofer, R., et al. (2007). The Arabidopsis DESPERADO/AtWBC11 transporter is required for cutin and wax secretion. Plant Physiol. 145, 1345-1360. doi: 10.1104/pp.107.105676

Panikashvili, D., Shi, J. X., Bocobza, S., Franke, R. B., Schreiber, L., and Aharoni, A. (2010). The Arabidopsis DSO/ABCG11 transporter affects cutin metabolism in reproductive organs and suberin in roots. Mol. Plant 3, 563-575. doi: $10.1093 / \mathrm{mp} / \mathrm{ssp} 103$

Panikashvili, D., Shi, J. X., Schreiber, L., and Aharoni, A. (2011). The Arabidopsis ABCG13 transporter is required for flower cuticle secretion and patterning of the petal epidermis. New Phytol. 190, 113-124. doi: 10.1111/j.14698137.2010.03608.x

Park, S., Li, J., Pittman, J. K., Berkowitz, G. A., Yang, H., Undurraga, S., et al. (2005). Up-regulation of $\mathrm{a} \mathrm{H}^{+}$-pyrophosphatase $\left(\mathrm{H}^{+}\right.$-PPase $)$as a strategy to engineer drought-resistant crop plants. Proc. Natl. Acad. Sci. U.S.A. 102, 18830-18835. doi: 10.1073/pnas.0509512102

Pasapula, V., Shen, G., Kuppu, S., Paez-Valencia, J., Mendoza, M., Hou, P., et al. (2011). Expression of an Arabidopsis vacuolar $\mathrm{H}^{+}$-pyrophosphatase gene (AVP1) in cotton improves drought- and salt tolerance and increases fibre yield in the field conditions. Plant Biotechnol. J. 9, 88-99. doi: 10.1111/j.1467-7652.2010.0 0535.x

Payyavula, R. S., Tay, K. H., Tsai, C. J., and Harding, S. A. (2011). The sucrose transporter family in Populus: the importance of a tonoplast PtaSUT4 to biomass and carbon partitioning. Plant J. 65, 757-770. doi: 10.1111/j.1365-313X.2010.04463.x

Peng, Y., Lin, W., Cai, W., and Arora, R. (2007). Overexpression of a Panax ginseng tonoplast aquaporin alters salt tolerance, drought tolerance and cold acclimation ability in transgenic Arabidopsis plants. Planta 226, 729-740. doi: 10.1007/s00425007-0520-4

Petrasek, J., and Friml, J. (2009). Auxin transport routes in plant development. Development 136, 2675-2688. doi: 10.1242/dev.030353

Pighin, J. A., Zheng, H., Balakshin, L. J., Goodman, I. P., Western, T. L., Jetter, R., et al. (2004). Plant cuticular lipid export requires an ABC transporter. Science 306, 702-704. doi: 10.1126/science.1102331

Poschet, G., Hannich, B., Raab, S., Jungkunz, I., Klemens, P. A., Krueger, S., et al. (2011). A novel Arabidopsis vacuolar glucose exporter is involved in cellular sugar homeostasis and affects the composition of seed storage compounds. Plant Physiol. 157, 1664-1676. doi: 10.1104/pp.111.186825

Quilichini, T. D., Friedmann, M. C., Samuels, A. L., and Douglas, C. J. (2010). ATP-binding cassette transporter G26 is required for male fertility and pollen exine formation in Arabidopsis. Plant Physiol. 154, 678-690. doi: 10.1104/pp.110.161968

Ravikumar, G., Manimaran, P., Voleti, S. R., Subrahmanyam, D., Sundaram, R. M., Bansal, K. C., et al. (2014). Stress-inducible expression of AtDREB1A transcription factor greatly improves drought stress tolerance in transgenic indica rice. Transgenic Res. 23, 421-439. doi: 10.1007/s11248-013-9776-6

Recorbet, G., Abdallah, C., Renaut, J., Wipf, D., and Dumas-Gaudot, E. (2013). Protein actors sustaining arbuscular mycorrhizal symbiosis: underground artists break the silence. New Phytol. 199, 26-40. doi: 10.1111/nph.12287

Reinders, A., Panshyshyn, J. A., and Ward, J. M. (2005). Analysis of transport activity of Arabidopsis sugar alcohol permease homolog AtPLT5. J. Biol. Chem. 280, 1594-1602. doi: 10.1074/jbc.M410831200
Remy, E., Cabrito, T. R., Baster, P., Batista, R. A., Teixeira, M. C., Friml, J., et al. (2013). A major facilitator superfamily transporter plays a dual role in polar auxin transport and drought stress tolerance in Arabidopsis. Plant Cell 25, 901-926. doi: 10.1105/tpc.113.110353

Rentsch, D., Schmidt, S., and Tegeder, M. (2007). Transporters for uptake and allocation of organic nitrogen compounds in plants. FEBS Lett. 581, 2281-2289. doi: 10.1016/j.febslet.2007.04.013

Ruiz-Lozano, J. M., Porcel, R., Bárzana, G., Azcón, R., and Aroca, R. (2012). “Contribution of arbuscular mycorrhizal symbiosis to plant drought tolerance: state of the art," in Plant Responses to Drought Stress, ed. R. Aroca (Berlin: Springer), 335-362.

Sade, N., Vinocur, B. J., Diber, A., Shatil, A., Ronen, G., Nissan, H., et al. (2009). Improving plant stress tolerance and yield production: is the tonoplast aquaporin SITIP2; 2 a key to isohydric to anisohydric conversion? New Phytol. 181, 651-661. doi: 10.1111/j.1469-8137.2008.02689.x

Samuels, L., Kunst, L., and Jetter, R. (2008). Sealing plant surfaces: cuticular wax formation by epidermal cells. Annu. Rev. Plant Biol. 59, 683-707. doi: 10.1146/annurev.arplant.59.103006.093219

Samuels, L., and McFarlane, H. E. (2012). Plant cell wall secretion and lipid traffic at membrane contact sites of the cell cortex. Protoplasma 249(Suppl. 1), S19-S23. doi: 10.1007/s00709-011-0345-7

Sanders, G., and Arndt, S. (2012). "Osmotic Adjustment Under Drought Conditions," in Plant Responses to Drought Stress, ed. R. Aroca (Berlin: Springer), 199-229. doi: 10.1007/978-3-642-32653-0_8

Sasaki, T., Mori, I. C., Furuichi, T., Munemasa, S., Toyooka, K., Matsuoka, K., et al. (2010). Closing plant stomata requires a homolog of an aluminum-activated malate transporter. Plant Cell Physiol. 51, 354-365. doi: 10.1093/pcp/pcq016

Schmitz, A. M., and Harrison, M. J. (2014). Signaling events during initiation of arbuscular mycorrhizal symbiosis. J. Integr. Plant Biol. 56, 250-261. doi: 10.1111/jipb.12155

Schulz, B. (2011). "Functional classification of plant plasma membrane transporters," in The Plant Plasma Membrane, eds A. S. Murphy, B. Schulz, and W. Peer (Berlin: Springer), 131-176.

Schulz, B., and Frommer, W. B. (2004). Plant biology. A plant ABC transporter takes the lotus seat. Science 306, 622-625. doi: 10.1126/science.1105227

Seo, P. J., Lee, S. B., Suh, M. C., Park, M. J., Go, Y. S., and Park, C. M. (2011). The MYB96 transcription factor regulates cuticular wax biosynthesis under drought conditions in Arabidopsis. Plant Cell 23, 1138-1152. doi: 10.1105/tpc.111.0 83485

Shirasawa, K., Takabe, T., Takabe, T., and Kishitani, S. (2006). Accumulation of glycinebetaine in rice plants that overexpress choline monooxygenase from spinach and evaluation of their tolerance to abiotic stress. Ann. Bot. 98, 565-571. doi: $10.1093 / \mathrm{aob} / \mathrm{mcl} 126$

Singh, R., Pandey, N., Naskar, J., and Shirke, P. A. (2014). Physiological performance and differential expression profiling of genes associated with drought tolerance in contrasting varieties of two Gossypium species. Protoplasma doi: 10.1007/s00709014-0686-0 [Epub ahead of print].

Surbanovski, N., Sargent, D. J., Else, M. A., Simpson, D. W., Zhang, H., and Grant, O. M. (2013). Expression of Fragaria vesca PIP aquaporins in response to drought stress: PIP down-regulation correlates with the decline in substrate moisture content. PLoS ONE 8:e74945. doi: 10.1371/journal.pone. 0074945

Szabados, L., and Savoure, A. (2010). Proline: a multifunctional amino acid. Trends Plant Sci. 15, 89-97. doi: 10.1016/j.tplants.2009.11.009

Taji, T., Ohsumi, C., Iuchi, S., Seki, M., Kasuga, M., Kobayashi, M., et al. (2002). Important roles of drought- and cold-inducible genes for galactinol synthase in stress tolerance in Arabidopsis thaliana. Plant J. 29, 417-426. doi: 10.1046/j.09607412.2001.01227.x

Takabe, T. (2012). Engineering of betaine biosynthesis and transport for abiotic stress tolerance in plants. J. Plant Biochem. Biotechnol. 21, 58-62. doi: 10.1007/s13562-012-0143-0

Ukitsu, H., Kuromori, T., Toyooka, K., Goto, Y., Matsuoka, K., Sakuradani, E., et al. (2007). Cytological and biochemical analysis of COF1, an Arabidopsis mutant of an ABC transporter gene. Plant Cell Physiol. 48, 1524-1533. doi: $10.1093 / \mathrm{pcp} / \mathrm{pcm} 139$

Vahisalu, T., Kollist, H., Wang, Y. F., Nishimura, N., Chan, W. Y., Valerio, G., et al. (2008). SLAC1 is required for plant guard cell S-type anion channel function in stomatal signalling. Nature 452, 487-491. doi: 10.1038/nature06608 
Verrier, P., Bird, D., Burla, B., Dassa, E., Forestier, C., and Geisler, M. (2008). Plant ABC proteins: a unified nomenclature and updated inventory. Trends Plant Sci. 13, 151-159. doi: 10.1016/j.tplants.2008.02.001

Wang, L. L., Chen, A. P., Zhong, N. Q., Liu, N., Wu, X. M., Wang, F., et al. (2014). The Thellungiella salsuginea tonoplast aquaporin TsTIP1;2 functions in protection against multiple abiotic stresses. Plant Cell Physiol. 55, 148-161. doi: $10.1093 / \mathrm{pcp} / \mathrm{pct} 166$

Wang, X., Li, Y., Ji, W., Bai, X., Cai, H., Zhu, D., et al. (2011). A novel Glycine soja tonoplast intrinsic protein gene responds to abiotic stress and depresses salt and dehydration tolerance in transgenic Arabidopsis thaliana. J. Plant Physiol. 168, 1241-1248. doi: 10.1016/j.jplph.2011.01.016

Wang, Y. F., Munemasa, S., Nishimura, N., Ren, H. M., Robert, N., Han, M., et al. (2013). Identification of cyclic GMP-activated nonselective Ca2+-permeable cation channels and associated CNGC5 and CNGC6 genes in Arabidopsis guard cells. Plant Physiol. 163, 578-590. doi: 10.1104/pp.113.225045

Watkins, J. M., Hechler, P. J., and Muday, G. K. (2014). Ethylene-induced flavono accumulation in guard cells suppresses reactive oxygen species and moderates stomatal aperture. Plant Physiol. 164, 1707-1717. doi: 10.1104/pp.113.233528

Wege, S., De Angeli, A., Droillard, M. J., Kroniewicz, L., Merlot, S., Cornu, D. etal. (2014). Phosphorylation of the vacuolar anion exchanger AtCLCa is required for the stomatal response to abscisic acid. Sci. Signal. 7, ra65. doi: 10.1126/scisignal.2005140

Weise, A., Barker, L., Kuhn, C., Lalonde, S., Buschmann, H., Frommer, W. B., et al (2000). A new subfamily of sucrose transporters, SUT4, with low affinity/high capacity localized in enucleate sieve elements of plants. Plant Cell 12, 1345-1355. doi: $10.1105 /$ tpc.12.8.1345

Wormit, A., Trentmann, O., Feifer, I., Lohr, C., Tjaden, J., Meyer, S., et al. (2006) Molecular identification and physiological characterization of a novel monosaccharide transporter from Arabidopsis involved in vacuolar sugar transport. Plant Cell 18, 3476-3490. doi: 10.1105/tpc.106.047290

Wu, L., Guan, Y., Wu, Z., Yang, K., Lv, J., Converse, R., et al. (2014). OsABCG15 encodes a membrane protein that plays an important role in anther cuticle and pollen exine formation in rice. Plant Cell Rep. 33, 1881-1899. doi: 10.1007/s00299-014-1666-8

Wudick, M. M., Luu, D. T., and Maurel, C. (2009). A look inside: localization patterns and functions of intracellular plant aquaporins. New Phytol. 184, 289-302. doi: 10.1111/j.1469-8137.2009.02985.x

Xu, C., Wang, M., Zhou, L., Quan, T., and Xia, G. (2013a). Heterologous expression of the wheat aquaporin gene TaTIP2; 2 compromises the abiotic stress tolerance of Arabidopsis thaliana. PLOS ONE 8:e79618. doi: 10.1371/journal.pone. 0079618

Xu, W., Jia, L., Shi, W., Liang, J., Zhou, F., Li, Q., et al. (2013b). Abscisic acid accumulation modulates auxin transport in the root tip to enhance proton secretion for maintaining root growth under moderate water stress. New Phytol. 197, 139-150. doi: 10.1111/nph.12004

Xu, Z. Y., Lee, K. H., Dong, T., Jeong, J. C., Jin, J. B., Kanno, Y., et al. (2012) A vacuolar beta-glucosidase homolog that possesses glucose-conjugated abscisic acid hydrolyzing activity plays an important role in osmotic stress responses in Arabidopsis. Plant Cell 24, 2184-2199. doi: 10.1105/tpc.112.095935

Xue, Y., Xiao, S., Kim, J., Lung, S. C., Chen, L., Tanner, J. A., et al. (2014). Arabidopsis membrane-associated acyl-CoA-binding protein ACBP1 is involved in stem cuticle formation. J. Exp. Bot. 65, 5473-5483. doi: 10.1093/jxb/eru304

Yamada, K., Osakabe, Y., Mizoi, J., Nakashima, K., Fujita, Y., Shinozaki, K., et al. (2010). Functional analysis of an Arabidopsis thaliana abiotic stress-inducible facilitated diffusion transporter for monosaccharides. J. Biol. Chem. 285, 1138 1146. doi: 10.1074/jbc.M109.054288
Yang, J., Isabel Ordiz, M., Jaworski, J. G., and Beachy, R. N. (2011). Induced accumulation of cuticular waxes enhances drought tolerance in Arabidopsis by changes in development of stomata. Plant Physiol. Biochem. 49, 1448-1455. doi: 10.1016/j.plaphy.2011.09.006

Yeats, T. H., and Rose, J. K. (2013). The formation and function of plant cuticles. Plant Physiol. 163, 5-20. doi: 10.1104/pp.113.222737

Yue, C., Cao, H., Wang, L., Zhou, Y., Hao, X., Zeng, J., et al. (2014). Molecular cloning and expression analysis of tea plant aquaporin (AQP) gene family. Plant Physiol. Biochem. 83, 65-76. doi: 10.1016/j.plaphy.2014.07.011

Zazimalova, E., Murphy, A. S., Yang, H., Hoyerova, K., and Hosek, P. (2010). Auxin transporters-why so many? Cold Spring Harb. Perspect. Biol. 2, a001552. doi: 10.1101/cshperspect.a001552

Zhang, H., Zhu, H., Pan, Y., Yu, Y., Luan, S., and Li, L. (2014). A DTX/MATEtype transporter facilitates abscisic acid efflux and modulates ABA sensitivity and drought tolerance in Arabidopsis. Mol. Plant 7, 1522-1532. doi: $10.1093 / \mathrm{mp} / \mathrm{ssu} 063$.

Zhang, L., Gao, M., Hu, J., Zhang, X., Wang, K., and Ashraf, M. (2012). Modulation role of abscisic acid (ABA) on growth, water relations and glycinebetaine metabolism in two maize (Zea mays L.) cultivars under drought stress. Int. J. Mol. Sci. 13, 3189-3202. doi: 10.3390/ijms13033189

Zhang, N., Si, H.-J., Wen, G., Du, H.-H., Liu, B.-L., and Wang, D. (2011). Enhanced drought and salinity tolerance in transgenic potato plants with a BADH gene from spinach. Plant Biotechnol. Rep. 5, 71-77. doi: 10.1007/s11816-010-0160-161

Zhang, Y., Wang, Z., Chai, T., Wen, Z., and Zhang, H. (2008). Indian mustard aquaporin improves drought and heavy-metal resistance in tobacco. Mol. Biotechnol. 40, 280-292. doi: 10.1007/s12033-008-9084-9081

Zhao, J., and Dixon, R. A. (2010). The 'ins' and 'outs' of flavonoid transport. Trends Plant Sci. 15, 72-80. doi: 10.1016/j.tplants.2009.11.006

Zhou, S., Hu, W., Deng, X., Ma, Z., Chen, L., Huang, C., et al. (2012). Overexpression of the wheat aquaporin gene, TaAQP7, enhances drought tolerance in transgenic tobacco. PLoS ONE 7:e52439. doi: 10.1371/journal.pone.0052439

Zhu, L., Guo, J., Zhu, J., and Zhou, C. (2014). Enhanced expression of EsWAX1 improves drought tolerance with increased accumulation of cuticular wax and ascorbic acid in transgenic Arabidopsis. Plant Physiol. Biochem. 75, 24-35. doi: 10.1016/j.plaphy.2013.11.028

Zhuo, C., Wang, T., Lu, S., Zhao, Y., Li, X., and Guo, Z. (2013). A cold responsive galactinol synthase gene from Medicago falcata (MfGols1) is induced by myoinositol and confers multiple tolerances to abiotic stresses. Physiol. Plant 149, 67-78. doi: 10.1111/ppl.12019

Conflict of Interest Statement: The authors declare that the research was conducted in the absence of any commercial or financial relationships that could be construed as a potential conflict of interest.

Received: 03 October 2014; accepted: 18 November 2014; published online: 04 December 2014.

Citation: Jarzyniak KM and Jasiński M (2014) Membrane transporters and drought resistance - a complex issue. Front. Plant Sci. 5:687. doi: 10.3389/fpls.2014.00687

This article was submitted to Plant Traffic and Transport, a section of the journal Frontiers in Plant Science.

Copyright () 2014 Jarzyniak and Jasinski. This is an open-access article distributed under the terms of the Creative Commons Attribution License (CC BY). The use, distribution or reproduction in other forums is permitted, provided the original author(s) or licensor are credited and that the original publication in this journal is cited, in accordance with accepted academic practice. No use, distribution or reproduction is permitted which does not comply with these terms. 